\title{
Kernos
}

Revue internationale et pluridisciplinaire de religion grecque antique

$18 \mid 2005$

Varia

\section{Los Pequeños Misterios de Agras}

Unos misterios órficos en época de Pisístrato

\section{Miriam Valdés Guía y Roxana Martínez Nieto}

\section{(2) OpenEdition}

1 Journals

\section{Edición electrónica}

URL: http://journals.openedition.org/kernos/872

DOI: $10.4000 /$ kernos.872

ISSN: 2034-7871

\section{Editor}

Centre international d'étude de la religion grecque antique

\section{Edición impresa}

Fecha de publicación: 1 enero 2005

Paginación: 43-68

ISSN: 0776-3824

\section{Referencia electrónica}

Miriam Valdés Guía et Roxana Martínez Nieto, «Los Pequeños Misterios de Agras », Kernos [En ligne], 18 | 2005, mis en ligne le 16 juin 2011, consulté le 19 avril 2019. URL : http://journals.openedition.org/ kernos/872 ; DOI : 10.4000/kernos.872 


\title{
Los Pequeños Misterios de Agras: unos misterios órficos en época de Pisístrato
}

\begin{abstract}
Résumé : Les Petits Mystères d'Agra: des mystères orphiques à l'époque de Pisistrate. La possibilité de reconnaître dans les Petites Mystères d'Agra des mystères orphiques dès le vi siècle peut s'appuyer sur des sources littéraires et iconographiques, et faire référence au contexte historique. Cette hypothèse correspond bien à la situation socio-culturelle de l'époque des Pisistratides où l'on voit se développer les cultes de Dionysos, Déméter/Gaia/Meter et Perséphone, ainsi que des textes comme ceux que la tradition attribue à Onomacrite.
\end{abstract}

\begin{abstract}
The Little Mysteries of Agra: Orphic Mysteries at the time of Peisistratos. The possibility of recognising Orphic elements in the Little Mysteries of Agra as early as the 6th century may be supported by evidence from literary and iconographic sources as well as from the historical context. This hypothesis ties in with the socio-cultural situation of Peisistratid times in which we can see the development of the cult of Dionysus and those of Demeter/Gaia/Meter and Persephone, and the flourishing of written texts, such as those attributed to Onomacritos.
\end{abstract}

\section{Introducción}

La inauguración de los Pequeños Misterios de Agras se ha venido asociando desde hace tiempo con los Pisistrátidas, especialmente a partir de los trabajos de J. Boardman ${ }^{1}$. Se ha resaltado especialmente la propaganda realizada por el tirano de la figura Heracles en varias de sus facetas, entre las que se encuentra la del héroe como iniciado en Eleusis, episodio que precede al de su katábasis, previa purificación por el asesinato de los Centauros, en la localidad de Agras. Los Pequeños Misterios fueron instaurados por Deméter, según varias narraciones, con esta finalidad ${ }^{2}$. En un trabajo reciente hemos retomado esta teoría para profundizar en la política de Pisístrato de integración en la ciudadanía, expresado o reflejado de forma simbólica en la apertura de algunas fiestas cívicas, como los Misterios. Éstos no sólo se hacen accesibles a los extranjeros (comúnmente aceptado y asumido), sino especialmente a las clases más bajas de la propia Atenas, los thetes, que se constituyen en un contingente importante de seguidores del tirano, considerado por Aristóteles el segundo prostates tou demou ${ }^{3}$. La iniciación de Heracles, el "portador de la maza", imagen del propio tirano y de su guardia,

\footnotetext{
1 J. Boardman (1972, 1975, 1989). D. Williams (1983); H.A. Shapiro (1989, 1990). S.B MATHESON (1994); A. VerbanCK-PIÉRARd (1995), p. 117; H. Lloyd-JonEs (1967): Katábasis de Heracles compuesta hacia mediados del s. VI.

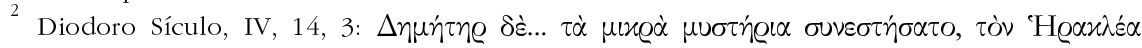
$\tau \iota \mu \tilde{\omega} \sigma \alpha$.

Aristóteles, Atheniensium Respublica, 28, 2. M. VALDÉs (2004).
} 
los korynephoroi ("portadores de maza"), en los Misterios, previa purificación en los Pequeños Misterios de Agras, es un medio del que se sirve Pisístrato para hacer iniciar en Eleusis a sus seguidores, entre los que se encuentran probablemente aquellos considerados de estirpe "impura" por Aristóteles ${ }^{4}$.

La cuestión que nos interesa ahora y que vamos a tratar de discernir es precisamente la naturaleza y las peculiaridades de estos Pequeños Misterios de Agras celebrados junto al Iliso, en Atenas; así como la posibilidad de que se formaran en estos momentos, incorporando ciertas leyendas y rituales que podrían considerarse ya propios del orfismo. Partimos además de las noticias que aluden a la presencia y actividad de personajes con conexiones órficas (Onomácrito el más famoso) en la corte de los tiranos.

El tema trata cuestiones especialmente debatidas dentro de los estudios sobre el orfismo. A saber: la antigüedad de parte de su literatura y la integración de ciertos elementos y rituales órficos dentro de la religión cívica (-oficial) en distintas poleis, entre las que se encuentra Atenas. Asimismo el contenido de este trabajo atañe a las relaciones entre el orfismo y el culto eleusino $^{6}$ sin olvidar, como veremos, las conexiones entre orfismo y dionisismo ${ }^{7}$.

En un artículo reciente R.P. Martin ha señalado la posibilidad de la recitación de poemas órficos en el contexto de fiestas o rituales públicos de la polis, en concreto en Atenas y desde la época de los Pisistrátidas (con

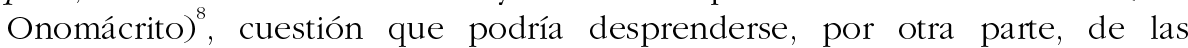
menciones "órficas" o "con conexiones órficas" en pasajes de la tragedia y de la comedia ática del $\mathrm{s}$. $\mathrm{V}^{9}$.

\footnotetext{
${ }^{4}$ Arist., Ath., 13, 5: "Formaban sus filas los que se habían visto privados de sus créditos, por su pobreza y los que no tenían pureza de linaje, por miedo. Lo evidencia el hecho de que, tras la caída de los tiranos, se realizó una revisión del censo, porque muchos participaban indebidamente de la ciudadanía. Cada uno de los partidos recibía su sobrenombre de los lugares en que trabajaba la tierra".

5 Señaló especialmente estas conexiones del orfismo con la corte de los Pisistrátidas: M.P. NiLSSON (1935) en un trabajo ya antiguo. Más recientemente puede verse también H.A. SHAPIRO (1989), p. 70 sq. Para la hipótesis de unos Pequeños Misterios órficos: E. SIMON (1966); ver más abajo nota 6. L. MALTEN (1909) supuso la composición de un himno a Deméter órfico en el entorno de Onomácrito en Atenas, que recogía las divergencias (así como el papel de Triptólemos) entre la versión del himno homérico y otras versiones posteriores.

F. GRAF (1974). P. BOYANCÉ $(1975,1993)$.

W. BURKERT (1977). M. Di MARCO (1993).

8 R.P. MARTin (2001): frente a posturas como la de M.L. WeSt (1983). Para Onomácrito puede verse también: P. BOYANCÉ (1993), p. 18 sq.; F. GRAF (1974), p. 147-149; M.L. WeSt (1983), p. 249 sq.; RE XVIII, 1 (1939), col., 491-493, s.v. "Onomakritos".

9 Por ejemplo en el pasaje de Aristófanes, Aves 693-702; Ver R.P. MARTin (2001), p. 32. M. DI MARCO (1993) señala, sin embargo, un proceso de gradual diferenciación, a partir de Pisístrato, entre orfismo y dionisismo oficial (con bibliografía anterior), aunque con el tirano confluyen y son favorecidas ambas corrientes (p. 143). Alusiones órficas en Heródoto, Esquilo, Eurípides, en especial en relación con los misterios de Dioniso: M.L. WeSt (1983), p. 260. Para orfismo en el Resos de Eurípides: C. PLICHON (2001).
} 
En este artículo vamos a argumentar la posibilidad de la recitación de poemas órficos en el seno de la fiesta celebrada en el mes Antesterion en Agras, los Pequeños Misterios, instituidos en época de los Pisistrátidas. Es posible, sin embargo, que la fiesta se constituyera sobre un fondo anterior, como postula Simon, que también asume un componente órfico en ella, como es la recitación del mito del nacimiento de Dioniso-Zagreo de Zeus y de Perséfone ${ }^{10}$

\section{Antigüedad del mito del desmembramiento de Dioniso y recitaciones órficas en fiestas áticas}

Los Pequeños Misterios no eran probablemente, como vamos a desarrollar más abajo, la única fiesta ática "oficial" o enmarcada dentro de lo que era la "religión cívica" de la polis ${ }^{11}$, en la que tenían lugar recitaciones órficas. También en el distrito de Flia se celebraban unos Misterios con conexiones órficas $^{12}$, de los que estaban a cargo la familia de los Licómidas, cuyos primeros miembros conocidos se remontan precisamente a la época de los Pisistrátidas ${ }^{13}$.

Existe otra fiesta oficial de Atenas en la cual, según una noticia de Filóstrato (Philostr., VA VI, 21), se recitaban poemas órficos: las Antesterias. El testimonio de Filóstrato, junto a otros rasgos de la fiesta, indica que la celebración pudo haber estado relacionada desde antiguo (posiblemente, al menos, desde el s. VI ó V), al igual que las Leneas, con el mito del desmembramiento de Dioniso y del renacimiento del dios, como supone Burkert ${ }^{14}$.

10 E. SIMON (1966) postula el nacimiento de Dioniso-Zagreo a partir de la escena de un vaso del s. IV a.C. (pelike de Leningrado 1859: J.D. BEAZLEY, $A R V^{2}, 1476,1$; H. MeTZger (1965), pl. 34, 2), en el que aparece en la cara A Deméter y Perséfone junto con otras deidades de Eleusis con Triptólemo y Heracles como iniciado; en la B Hermes recibe al niño divino de la diosa y aparece Atenea como protectora del niño. Interpretación aceptada por J.D. BEAZLEY (1971), p. 496. Analizado y discutido en F. GRAF (1974), p. 66 sq., que prefiere ver en el vaso un reflejo de un texto órfico que narrara este mito más que la alusión a una fiesta de Atenas; puede verse también P. BOYANCÉ (1975). Para otras interpretaciones del vaso: E.R. FARNELl (1977), vol. III, p. $253 s q$.

${ }^{11}$ Religión de la polis: Ch. SOURVINOU-INWOOD (2000a y 2000b).

I. LOUCAS y E. LOUCAS (1986); I. LOUCAS (1990). Flia: Pausanias, I, 31, 4. Licómidas y orfismo (himno a Deméter compuesto por Museo para los Licómidas): Paus., I, 22, 7; IV, 1, 5; IX, 27, 2 y IX, 30, 12: los Licómidas cantan himnos órficos en sus rituales.

13 H.A. Shapiro (1989), p. 72. J.K. DAvies (1971), p. 211 sq. y 346 sq. Para Licómidas puede verse también: R. BOEHME (1991).

${ }^{14}$ La primera mención explícita del mito de la muerte de Dioniso se halla en Calímaco (ver más abajo nota 72), pero se puede encontrar ya una alusión a ella en Píndaro (fr. 133.1: $\pi$ cív $\alpha \nu^{\circ}$ $\pi \alpha \lambda \alpha \iota 0 \tilde{~} \pi \varepsilon ́ v \theta \varepsilon 0$ ) y quizás en el himno homérico a Dioniso (ver la nota 16). En las Antesterias: W. BurkerT (1983), p. 224-226; W. BurkerT (1985), p. 239 (quizá el mito del desmembramiento sea tan antiguo como la misma fiesta de las Antesterias). I. LADA-Richards (1999), p. 96. Sparagmos en las Leneas: sch., Clemente de Alejandría Protreptico I, 2. En relación a Iaco: Luciano, Peri orcheseos, 39. En un trabajo anterior señalábamos que los mitos de despedazamiento y/o renacimiento-rejuvenecimiento en un caldero (como el de Pelias a manos de sus hijas, Pélope inmolado por Tántalo, Árcade por Licaón que trajo como consecuencia el diluvio, rememorado, por cierto, en las Antesterias, y Tiestes por Atreo) son muy antiguos en Grecia y 
Aunque recientemente se ha puesto en duda la existencia misma del mito órfico de Dioniso-Zagreo desmembrado por los titanes, su presencia en las fuentes antiguas es clara como ha demostrado Bernabé, quien señala, del mismo modo que Burkert, que posiblemente era ya conocido por Píndaro. Bernabé tampoco descarta la posibilidad de que pudiera remontarse al s. VI, como se señala en un testimonio de Pausanias (VIII, 37, 5), quien lo vincula con Onomácrito. ${ }^{15}$

La probable referencia en el himno homérico a Dioniso (que parece remontarse, al s. VI) al triple nacimiento del dios y/o al mito del descuartizamiento del mismo ${ }^{16}$, llevó a Barigazzi ${ }^{17}$ a postular como autor del himno a Onomácrito, quien según Pausanias introdujo la figura de los titanes en este mito $^{18}$. Si bien aceptamos con Cassola $^{19}$ la improbabilidad de atribuir a Onomácrito el himno homérico a Dioniso (donde el dios es, además, hijo de Sémele y no de Perséfone ${ }^{20}$ ), lo interesante es señalar la posibilidad de la circulación ya en estos momentos (s. VI) de versiones del mito del desmembramiento de Dioniso, en conexión con fiestas y rituales como Leneas y Antesterias en el Ática, o las celebraciones de Dioniso Liknites en Delfos ${ }^{21}$.

están, en algunos casos, conectados con el dios Dioniso (Penteo, Driante, Hipaso que mueren desmembrados por sus familiares víctimas de Dioniso, o Learco y Melicertes): M. VALDÉs (1998). Esto lleva a pensar que también Dioniso pudo haber sido objeto de desmembramiento (en forma de animal, normalmente un cabrito) y renacimiento (en un caldero) en el contexto de fiestas muy antiguas como Leneas, Antesterias o las de Dioniso Liknites en Delfos (ver nota 21); esto parece sugerir, en efecto, la estructura y el contenido de las Antesterias: W. BURKERT (1983), p. 213 sq. (que lo equipara con el vino); M. VALDÉs (1998).

15 R.G. EDMONDS (1999). Criticado en A. BERnABÉ (2002) que recoge de forma exhaustiva todas las fuentes. Para el fragmento de Píndaro ver nota anterior. W. BURKERT (1983), p. 225, n. 43 .

Fecha del himno a Dioniso: F. CASsOla (1975), p. 16 (entre la mitad del s. VII y la mitad del s. VI). A. BARIgAzZi (1963); F. CASSOla (1975), p. 15-16; M. Di MARCO (1993). Se han reconocido en el v. 11 (que alude a la fiesta trietérica) o bien los tres nacimientos del dios ( $\omega \varsigma \zeta \delta$ $\tau \grave{\alpha} \mu \dot{\varepsilon} \nu \tau$ ¡ía. F. CASSOLA [1975], p. 15) o, una posible alusión al desmembramiento del dios, "cortar al niño en tres trozos": A. BARIGAZZI (1963) que sustituye tamen (en lugar de ta men) por tamon. Ver también D.M. Cosi (2000), p. 158

17 A. BARIGAZZI (1963).

18 Paus., VIII, 37, 5: "Onomácrito ha tomado de Homero el nombre de los Titanes, ha instituido un culto orgiástico en honor de Dioniso y ha hecho de los Titanes los artífices de la pasión de Dioniso".

F. CASSOla (1975), p. 16

20 Sin embargo Dioniso como hijo de Sémele no es incompatible con el mito de Dioniso, hijo de Perséfone. Así lo demuestra la unión de ambas tradiciones en los himnos órficos, que podría ser según J. RUDHARDT (2002), bastante anterior (¿tal vez ya desde el himno homérico?: ver nota 16).

${ }^{21}$ La fiesta de Dioniso Liknites era representada ya posiblemente en escenas de Delfos del 530 a.C.: P.G. Themelis (1992), p. 65 sq. (con el liknon). Dioniso Liknites desmembrado y enterrado en Delfos: Plutarco, Isis y Osiris, 365a. Véase también R. SEAFORD (1981), p. 266 (supone la existencia de un ritual antiguo en Delfos de desmembramiento y renacimiento del dios). Para Liknites en Delfos: M. DARAKI (1985), p. 20 sq. (con alusión igualmente a Leneas y Antesterias); W. BURKERT (1983), p. 123-126 (que también lo relaciona con el mito de desmembramiento del dios). Entre los himnos órficos tardíos hay uno dedicado a Dioniso Liknites y otro 
Ello hace plausible y creíble una elaboración o reelaboración "órfica" de esta leyenda por parte de Onomácrito, quien trabaja junto a otros personajes con conexiones órficas, procedentes de la Magna Grecia (Orfeo de Crotona y Zópiro de Heraclea $^{22}$ ) en la Atenas de los Pisistrátidas ${ }^{23}$.

Por otra parte, a pesar de que no tenemos constancia de la existencia de una versión "órfica" de la leyenda eleusina hasta el s. IV, en la que aparecen personajes como Disaules, Baubo, o el mismo Triptólemo (hijo de Disaules), Richardson ha puesto de manifiesto la posibilidad de que esta leyenda órfica de Eleusis no sea más que el desarrollo de una versión local más "popular" o menos aristocrática que la del himno homérico, luego ática ${ }^{24}$. En el artículo sobre Pisístrato que mencionábamos al principio, hemos señalado la coincidencia del inicio del desarrollo de la figura de Triptólemo con la política de los tiranos ${ }^{25}$, así como su presencia, en el caso de Disaules, en Argos, de donde procede una parte importante del contingente de los "aliados" del tirano en su tercera toma de poder $^{26}$. Si se tiene en cuenta la actividad de personajes con carácter órfico en estos momentos, cabe postular la hipótesis del inicio del desarrollo de la leyenda órfica eleusina a partir de versiones locales vinculadas con diversas fiestas de esta localidad, como es el caso de la figura de Triptólemo ${ }^{27}$.

La hipótesis de la circulación de una literatura órfica, p.e. los oráculos de Museo manipulados por Onomácrito ${ }^{28}$, hacia la segunda mitad del s. VI en Atenas, en relación con rituales y fiestas "cívicos" promocionados por los Pisistrátidas, (especialmente los de Dioniso y Deméter), repercute también en los Pequeños Misterios de Agras, en los que nos vamos a centrar a continuación.

a Dioniso Perikionios: G. Ricciardelli (2000), no 46 y 47 (también a Dioniso Leneo no 50). Para Dioniso Liknites: DIETRICH (1958). Leneas y Antesterias: ver nota 14.

22 W.K.C. GUTHRIE (1970), p. 220. M. Di MARCO (1993), p. 143.

23 H.A. SHAPIRO (1990). D. Plácido (1993), p. 190.

${ }^{24}$ Lo único que admite Pausanias como obra auténtica de Museo es el himno a Deméter compuesto para el genos de los Licómidas (ver más arriba, nota 10), antigua familia originaria de Flia, al norte del Ática (cf. Paus., I, 31, 4). N.J. Richardson (1974), p. 81 sq. F. GRAF (1974), p. 158 sq. M. VALDÉs (2004), n. 56. Versión órfica con estos personajes: KERN, fr., 51 y 52 . Ver más arriba nota 3. versión "órfica" de la leyenda eleusina hasta el s. IV: Asklepiades de Tragilos FGrH 12 F 4. Triptolemo, hijo de Disaules: Paus., I, 14, 3

25 M. VAldÉs (2004). Para Triptólemo con los Pisistrátidas: N.J. RiCHARDSON (1974), p. 9 y 194; H.A. Shapiro (1989), p. 76-7. K. Clinton (1992), p. 41 sq.; id. (1994), p. 164 sq. S.B. MATHESON (1994). LIMC VIII, 1 (s.v. "Triptolemos"), p. 56 sq..

${ }^{26}$ Para leyendas argivas: M. PIÉRART (2000), aunque atribuye el desarrollo de las mismas al s. V. Sobre el contingente de "aliados" del tirano de Argos: Heródoto, I, 61, 4; Arist., Ath, 17, 4; Timonassa: Arist., Ath., 17, 3; Hdt., V, 94. Disaules en Argos: Paus., II, 14; Paus., I, 14, 2-3.

27 Triptólemo en Proerosias: N. ROBERTSON (1996). En Tesmoforias: K. Clinton (1994), p. 163 , n. 17

${ }^{28}$ Hdt., VII, 6. Para Museo: P. Boyancé (1993), p. 21 sq.; M.L. West (1983), p. $249 s q$. (escepticismo acerca de la actividad de Onomácrito, en relación con el orfismo, en la Atenas de los Pisistrátidas). F. GRAF (1974), 9 sq. P. BOYAnCÉ (1975). Para la figura y los escritos atribuidos a este personaje: R.B. MARTínez NieTo (2000), p. 139-143, esp. 142, n. 20; R.B. MARTíneZ NiETO (2001). 


\section{Los Pequeños Misterios y el culto a la Madre en Atenas}

El primer testimonio de los mismos puede ser, como han supuesto Boardman y Shapiro, un vaso del 540 a.C. aproximadamente ${ }^{29}$, en el que junto a Heracles (representado en su aventura en el Hades, en búsqueda de Cerbero) aparecen personajes eleusinos como Deméter, Hermes, Triptólemo y una figura barbada con cetro, cuyo nombre, inscrito en el vaso, "Plutodotas", tiene conexiones interesantes tanto desde un punto de vista órfico", como en relación con Eleusis y con esta zona del Iliso, Agras $^{31}$.

Disponemos de muy pocas referencias antiguas ${ }^{32}$ a los Pequeños Misterios $^{33}$. La celebración probablemente tenía lugar en el Metroon de Agras, consagrado a la diosa Deméter, asimilada a su vez a la Madre de los dioses. Existen restos de un templo de mediados del s. V que podrían identificarse como Metroon, aunque otros autores lo atribuyen a Ártemis ${ }^{34}$. Otra posibilidad, dada la intervención de los Pisistrátidas en la zona del Iliso, como veremos más adelante, sería el probable establecimiento en estos momentos de los Pequeños Misterios, para iniciar a Heracles promocionado por los Pisistrátidas. De este modo, el lugar habría quedado inaugurado como espacio para la celebración de dichos Misterios.

Generalmente se asume que el culto a la Madre se inicia en Atenas hacia el $525 / 500^{35}$. Sin embargo, recientemente, L'Homme-Wéry ${ }^{36}$ ha señalado la posibilidad de que el culto se remonte al menos a mediados del s. VI, aunque ella postula, incluso, que se habría inaugurado ya con la reorganización de Solón. Uno de los indicios que apuntan al conocimiento del culto de la Madre en Atenas a mediados del s. VI es un ánfora ática de figuras negras del 540/30

29 LIMC IV, 1, n 1405 p. 806. Lo relacionan con los Pequeños Misterios: J. BOARDMAN (1975). H.A. SHAPIRO (1989), p. 78-89. S.B. MATHESON (1994), p. 364. Para otra interpretación: H. METZGER (1965), p. 8-10 (pl. I, 2 y II, 1 y 2). E. SiMON (1997), p. 98 (fig 1).

30 En un himno órfico Zeus es llamado Miliquio y Plutodotas: G. Ricciardelli (2000), nº 73.

31 M. VALDÉs (2004), esp. n. 47. Para el culto a Zeus en esta zona de Agras: M. VALDÉS (2002c).

${ }^{32}$ Sch. Ar., Pl., 845; Sch. Platón, Gorgias, 497c. Estacio, Tebaida, 8.763 sq.; Plut., Demetrio, 26; Clem. Al., Stromata V, 11, 71, 1. En Agras: Esteban de Bizancio, s.v. Agra; Eustacio, Sch. Il., II, 361, 37-39; Polieno, V, 17, 1. Templo de Deméter: Hesiquio, s.v. Agrai; Suda, s.v. Agra; An. Gr. Bekker, I, 327, 3 (Metroon de Agras). Para una compilación de fuentes sobre Agras y el Metroon: P. Chantraine (1956).

33 G. FOUCART (1914), p. 297 sq; L. DeUbner (1932), p. 70; G. MYlOnAs (1961), p. 239 sq; (bastante escéptico con respecto al papel desempeñado por Dioniso); K. KERÉNYI (1967), p. 45 sq.; N.J. Richardson (1974), p. 21; A.C. Brumfield (1981), p. 139 sq.; G.S. SFAMENi (1986), p. 62 $s q$; R.M. SIMMS (1980), p. 60 sq.

34 H. MÖBIUS (1935/6), p. 234 sq; N. Frapicini (1987), p. 24; J. Travlos (1971), p. 112-113 (con bibliografía anterior) considera, sin embargo, que se trata del templo de Ártemis Agrótera, postulando que el Metroon se hallaría más cercano al Iliso. Puede verse también C.A. PICón (1978), aunque no se pronuncia sobre a qué divinidad pertenecía el templo. Fuentes para el Metroon de Agras: IG I $\mathrm{I}^{3}, 383$, II, 50; An. Gr. BEKKER, I, 327, 3 - Cleidemo, FGrH 323 F 1.

35 R. PARKER (1996), p. 190. Este autor postula que el culto no se inaugura en los Pequeños Misterios hasta el 460: p. 188.

\footnotetext{
36 L.M. L'HOMME-WÉrY (2000), p. 28 sq.
} 
que tradicionalmente se ha interpretado como la representación de la diosa, dada su similitud con el grupo de imágenes de la Madre, posiblemente copiadas de xoana de culto. En estas imágenes la diosa aparece con frecuencia situada junto a un león, en un naiskos o templete ofrendado a la Madre. Sus lugares de culto se remontan a la primera mitad del s. VI y se encuentran en ambiente eolio y jonio ${ }^{37}$. Otros autores han rechazado que el vaso ático represente a la diosa, ya que la aparición de trípodes podría indicar, más bien, según Shapiro, un culto de Apolo en el Pition inaugurado por los Pisistrátidas ${ }^{38}$. Aun admitiendo esta posibilidad, el hecho de la presencia del león en el vaso, así como de columnas eólicas, muestra al menos una clara influencia eolia y frigia y el conocimiento, por tanto, del culto de la Madre, expandido, por otro lado ya en el s. VI, posiblemente desde principios del mismo y quizás desde antes, tanto en el Peloponeso como en ambiente de la Magna Grecia ${ }^{39}$. Cabría pensar, según Naumann, que una estatua de mármol de una mujer descubierta en la Acrópolis del 550 represente también a la diosa ${ }^{40}$. Por otra parte, la aparición de un león en otro vaso de figuras negras junto a Deméter y Core, que llevan en sus manos espigas de trigo $^{41}$, apunta a una asimilación temprana entre la Madre y la diosa eleusina en Atenas, por lo que no debería extrañar la hipotética presencia de la diosa frigia identificada con Deméter en unos Misterios celebrados junto al Iliso (como el Pition de Apolo), dedicados también a Deméter y Core, en un lugar conocido ya con seguridad como Metroon en el s. V.

El culto de la Madre que generalmente se hace remontar al 525/500 es el del ágora nueva del Cerámico, situado en el Metroon junto a la sede del Consejo. Con este culto del ágora es con el que L’Homme-Wéry asocia las medidas de Solón, retomando y modificando la antigua teoría de Thompson del inicio de un culto a Deméter, vinculada al Consejo ya desde estos

37 J.D. BeAZley, ABV 326 London B 49; K. SCHEFOld (1937), p. 38, fig. 5. Para la imagen del vaso de Atenas: F. GRAF (1984) p. 118, n. 13. Más cauteloso para interpretar en esta imagen a la Madre de los dioses: F. NAumann (1983), p. 117.

38 H.A. SHAPIRO (1989), p. 59 (pl., 29c); N. FrAPICINI (1987), p. 20-21 (excluye que sea Méter pero no propone una solución alternativa); R. PARKER (1996), p. 191, n. 141.

39 F. GRAF (1984); id. (1985), p. 107-115; R. PARKER (1996), p. 191, n. 140; L.M. L'HOMMEWéry (2000), p. 28. Peloponeso: J. DE LA GENIÈRE (1986, 1993). En Locrio Epizefirio inscripción de Cibeles de finales del s. VII: J. DE LA GENIÈRE (1985): sugiere que el culto de la diosa frigia llegaría vía Esparta.

F. NAUMANN (1983), p. 145-146 (cat., no 111, taf., 19, 3). J. DE LA GENIÈRE (1985), p. 696 ; ead. (1986), p. 32 (señala también la presencia de pequeñas figurillas femeninas sentadas con un león en sus rodillas, como podría haber estado la estatua de la Acrópolis); también ROLLER (1999), p. 133); FrAPICCINI (1987), p. 16-17 (propone que se trata de un culto privado). L.M. L'HommeWÉRY (2000), p. 30, n. 54.

41 J.D. BeAzley, $A B V$ 705, 39; H. Metzger (1965), p. 22, no 43. LIMC IV 1, addenda, s.v. "Demeter", p. 864, n 216 (L. BESCHI): Deméter y Core estantes y con espigas junto a un león (del 500 a.C. aprox.). Ver en relación con este vaso y la temprana identificación de Deméter (Deo) y Rea en Atenas (en concreto referido a los Misterios de Flia): I. LOUCAS, E. LOUCAS (1986), p. $397 s q$ 
momentos en el ágora ${ }^{42}$. En otro lugar hemos señalado la cercanía de Deméter y Gea (también en su lugar de culto entre la Acrópolis y el Areópago), llamada por Solón la "Gran Madre de los dioses olímpicos", y la conexión que se establece entre ambas diosas y Méter ${ }^{43}$. Sea con Solón o con Pisístrato, ambos interesados en una política de acercamiento al mundo jonio $^{44}$, y gracias a quienes se introdujo el culto de la Madre, lo cierto es que la integración de la diosa frigia en Atenas se debió realizar a través de su asimilación y/o asociación tanto con Deméter ${ }^{45}$ como con Gea. El acercamiento entre Gea y Deméter (que se refleja en la influencia del himno homérico a Deméter sobre el de $\mathrm{Gea}^{46}$ ) puede observarse asimismo en el distrito de Flia,mencionado más arriba como lugar de desarrollo de un culto mistérico con conexiones órficas, y sede de un culto a Rea, Deméter Anesídora y Gea, llamada la Gran diosa, entre otras divinidades ${ }^{47}$.

La inauguración, por tanto, de este espacio en el distrito de Agras junto al Iliso como Metroon en época de Pisístrato, tal vez hacia el 540-530 a.C. coincidiendo con el vaso citado de Reggio que haría alusión a los Pequeños Misterios y en el que aparece también Deméter, no resultaría extraña teniendo en cuenta que los Pisistrátidas dedican una atención y un cuidado especiales a las construcciones de esta zona del Iliso ${ }^{48}$. Este área de la ciudad se asocia, por otra parte, con la basileia de época oscura (los Neleidas), a la que se hallan vinculados ideológicamente los tiranos de Atenas. ${ }^{49}$

\section{Unión de Deméter/la Madre - Zeus en los Pequeños Misterios y en el Papiro de Derveni}

Aunque los pequeños Misterios tenían lugar en el Metroon, la fiesta estaba dedicada de forma especial a Perséfone ${ }^{50}$. Lo que vamos a proponer, a partir

\footnotetext{
42 L.M. L’HOMme-Wéry (2000), p. 28 sq. H.A. THOMPSON (1937), p. 205. Puede verse también: R. MARTIN (1951), p. 273.

${ }^{43}$ M. VAlDÉs (2001), p. 106; ead. (2002a), p. 36. Para el culto de la Madre puede verse. E. Will (1960), p. 103 (Gea como la Gran Madre de todo en el himno homérico a la diosa del s. VI). Ph. Borgeaud (1996). Gea y Deméter junto al Areópago: Paus., I, 22, 3.

44 Posibilidad de viajes de Solón a Asia Menor: A.J. Domínguez Monedero (2001), p. 100 sq. Pisistrátidas y mundo jonio: A. ALONI (1989).

${ }^{45}$ Para la relación estrecha entre el culto de la Madre del ágora, el Bouleuterion y el culto de Deméter eleusina puede verse: M. VALDÉs (2002a), p. 37, n. 74 y p. 232, n. 88; R. PARKER (1996), p. 189 , n. 134 .

${ }_{47}^{46}$ J. Humbert (1936), p. 239 sq.; I. LOUCAS, E. LOUCAS (1986), p. 399 sq.

47 Paus., I, 31, 4: Apolo Dionisodotos (don de Dioniso), Ártemis Selasphoros (portadora de la llama), Dioniso Anthios (florido), Ninfas Isménides, Zeus Ctesios, Atenea Tithronion, Core Protogone (la primer nacida) y las diosas que llamamos Semnai. Para Flia véase más arriba nota 12 y nota anterior.

${ }^{48}$ Pition y Olympieon, lugar de culto este último también de Rea y Gea: Paus., I, 18, 7. R.E. WYCHERLEY $(1963,1964)$

49 H.A. SHAPIRO (1983).

50 Dedicada a Perséfone: Sch., Aristófanes, Ploutos, 845f, 2: "existían los grandes (Misterios) de Deméter y los pequeños de Perséfone...". Duris (historiador samio) dice que la "diosa Deméter llega para celebrar los misterios de su hija": Ateneo, VI, 253d (Duris de Samos, FGrH 76
} 
principalmente de la información que proporciona un escolio a Platón, es que en ellos se celebraba (probablemente con recitaciones pero también con representaciones) el rapto de Perséfone por Plutón, la unión de Zeus y Deméter y posiblemente también la unión de Zeus con Perséfone, el nacimiento de Dioniso y el mito de su desmembramiento por parte de los titanes. Es decir, la información proporcionada por este escolio apunta claramente a la celebración de unos misterios órficos, en los que se unen tanto las leyendas referentes a Eleusis (Deméter y Core) como las de Dioniso (más desarrolladas en la misma ciudad de Atenas en celebraciones cercanas como las Antesterias).

Sch., Platón, Gorgias, 497c:

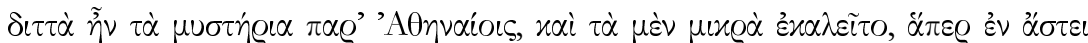

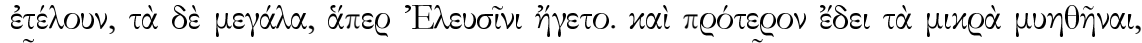

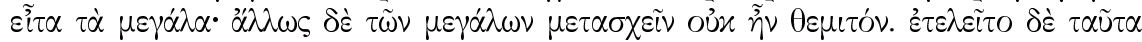

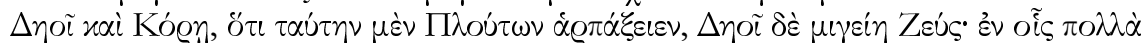

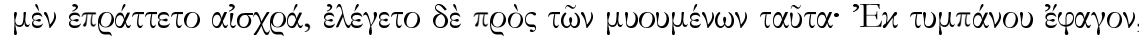

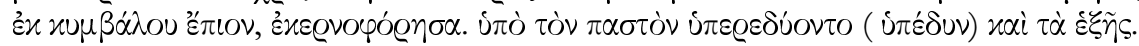

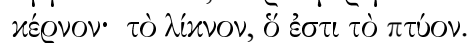

Dos eran los Misterios entre los atenienses: unos eran llamados Pequeños, los cuales celebraban en la ciudadela; otros Grandes, los que tenían lugar en Eleusis. Era necesario iniciarse primero en los Pequeños y luego en los Grandes. De otro modo que no fuera ese no estaba permitido participar en los Grandes (Misterios). Estos se celebraban en honor de Deo ${ }^{51}$ y Core, porque Plutón la raptó (a Perséfone) y Zeus se unió con Deo (Deméter). En ellos se realizan muchas cosas vergonzosas, y a los que se iban a iniciar se les decía esto: "comí en el tambor, bebí en el címbalo, llevé los vasos sagrados; penetré en la cámara nupcial”. Y Y lo que sigue.

(kernon) plato de barro: (liknon) cesta ancha en la que se colocaba el maíz después de ser trillado, utilizada para ventearlo y separarlo de la cáscara.

La clave para defender las conexiones órficas de los Pequeños Misterios a partir de este texto se encuentra principalmente en la referencia a la unión de

F 13). Hipólito, Refutatio omnium haeresium V, 843 ("pequeños, dicen, son los misterios de Perséfone").

51 Deo es otro apelativo para Deméter que aparece ya en el Himno homérico (v. 47, 211, 493). También se encuentra en la Helena de Eurípides (v. 1343) en un pasaje en el que la diosa Deméter se asimila a Méter o Cibeles.

52 A.J. Festugière (1935, p. 382) analizó parte de este texto reproducido en Clemente, Protréptico (ver más abajo nota 67), a propósito del análisis de la expresión $\Delta \varepsilon \sigma \pi o i ́ v \alpha \varsigma$ úiò

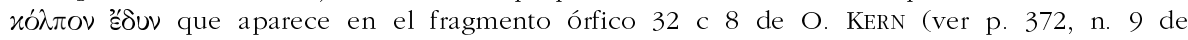

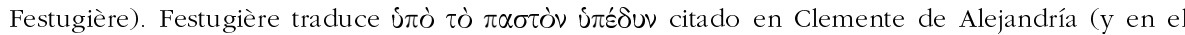
escolio de los Pequeños Misterios) como: "je suis descendu dans la chambre (de la déesse)". Señala que pastos describe la cripta subterránea, las cavernas de montaña (como thalamai: "lugares sagrados subterráneos dedicados a Rhea": en schol. Nic., Al., 6-8), lo que significaría, según él, tanto en el fragmento órfico como en el del Protréptico que el mystes desciende al seno de la diosa (en el caso de Perséfone: referencia a "muerte" del mystes). Ver también comentario de P. SCARPI (2002), D 55, p. 147. Además de Clemente de Alejandría, Fírmico Materno reproduce parte del texto: De errore profanarum religionum, 18, 1. 


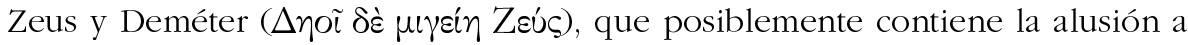
un contexto mítico más amplio en el que puede entenderse también el resto de las noticias que proporciona el escolio, así como otras que luego veremos.

La posibilidad de que la literatura óffica y, en concreto, una teogonía órfica se remonte a finales del s. VI fue observada por West en su análisis sobre el Papiro de Derveni, quien habría citado o tomado el material de lo que él llama "Protogonos theogony" papiro es abundantísima. En un artículo reciente sobre el mismo Bernabé $e^{54}$ se ha centrado de forma especial en el comentario al poema recogido por el papiro que se atribuye a Orfeo, el cual, como afirmaba ya West, puede remontarse a finales del s. VI, aunque señala que no se trataría tanto de una teogonía sistemática, como de un poema corto que presupone la existencia de otros conocidos por el autor sobre el mismo tema. El comentario a un poema órfico recogido por este Papiro constituye el testimonio órfico más antiguo del que se tiene noticia ${ }^{55}$. En él se describe especialmente la primacía y el reinado de Zeus. Tras la recreación del mundo por parte del dios, el poema termina con la unión incestuosa de éste con su madre (a la que no se da nombre en el poema), normalmente conocida como Rea, pero identificada en las Rapsodias con Deméter. También en el comentario se identifica a Rea con Deméter y con la Madre Tierra ${ }^{56}$. Aunque Bernabé señala la conveniencia de ser cautelosos y de no atribuir, sin más, a la diosa madre del poema la identidad de Deméter, algunos indicios (además de las indicaciones del propio comentarista del poema) permiten sospechar o postular ya esta identidad.

Más arriba se ha señalado la confluencia que existe en el Ática entre los cultos de Deméter, la Madre de los dioses y la Tierra, Gea, en el Metroon del ágora, posiblemente en Flia, y sobre todo en el Metroon del Iliso, lugar de la celebración de los Pequeños Misterios (y por tanto lugar de culto de Deméter y Core). La confluencia y asimilación entre la Madre de los dioses y Deméter (llamada Deo) se refleja ya en la Helena de Eurípides y puede remontarse incluso al s. VI a partir del vaso, analizado más arriba, en el que se representa a Deméter y Core con un león ${ }^{57}$. Por otra parte, aun cuando no se acepte la teoría de L'Homme-Wéry acerca de la introducción del culto a la Madre de los dioses en el s. VI en el Ática, las conexiones de esta diosa con Deméter y los

53 M.L. WEST (1983), p. 93.

A. BERNABÉ (1999).

55 A. BERnABÉ (1999), p. 309: se remonta a finales del s. VI.

A. BERNABÉ (1999), p. 332.

57 Eur., Hel., 1300 sq.: "Hace tiempo, la Madre montaraz de los dioses" (Deméter, identificada aquí con Rea Cibeles en audaz y curioso sincretismo religioso, ya que el ritual descrito en esta escena es dionisíaco); " cuando la Madre quiso poner fin al cansancio de sus carreras... después de haber buscado en vano al raptor de su hija; Zeus, intentando apaciguar la cólera de la Madre...; te atrajiste la ira de la Gran Madre..." Cf. G. CERRI (1983). Para el vaso y la identificación temprana de la Madre con Deméter ver más arriba nota 41. 
Misterios desde su santuario (Metroon) del ágora, edificado hacia el 500, son evidentes $^{58}$.

Demasiados elementos confluyen como para no poder decir, con coherencia, que la "madre" a la que se une Zeus en el himno órfico del Papiro de Derveni de finales del s. VI pueda ser Deméter-Méter: en primer lugar la posibilidad de la inauguración de un culto a la "Madre" en el s. VI en el Ática en estrecha conexión con el culto de Deméter eleusina y de Gea; a esto se añade la hipótesis de la inauguración de los Pequeños Misterios (celebrados en un "Metroon" de la Madre, al menos desde el s. V) en el s. VI con Pisístrato (para purificar a Heracles), así como la noticia del escolio a Platón de que Zeus se unía a Deméter (o Deo) en estos Pequeños Misterios; y por último, las noticias que aluden claramente a la actividad de personajes con conexiones órficas en la corte de los Pisistrátidas y a la circulación en esos momentos de un himno a Deméter atribuido a Museo, compuesto para los Licómidas de Flia donde se veneraba a Rea y a Gea, además de a Deméter, y cuyo telesterion se remonta a época anterior a las guerras médicas ${ }^{59}$.

\section{Zeus, Perséfone y Dioniso en los Pequeños Misterios}

Más difícil es aceptar la existencia ya en estos momentos de literatura órfica que hiciese referencia a la continuación de la historia (es decir la unión de Zeus y Perséfone y el nacimiento de Dioniso), al menos en el comentario al poema citado por el Papiro de Derveni ${ }^{60}$. Sin embargo, la mención de la unión de Zeus y Deméter en unos Misterios dedicados a Perséfone, no tiene sentido si en ellos se narraba (y/o representaba) sólo el rapto de Core por Plutón, como se especifica en el escolio (mito del que existe también una versión órfica ${ }^{61}$ ). Por otra parte, la aceptación de una continuación de la historia en la celebración de los Pequeños Misterios (unión a Deméter, unión a Perséfone, nacimiento de Dioniso, desmembramiento de Dioniso: mitos y ritos a los que se referiría el escolio cuando alude a que "muchas cosas vergonzosas o inefables se realizaban") ayudaría a explicar la noticia que

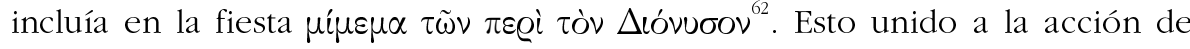

58 Notas 42 y 45.

99 Juliano, Or. V, 159a iguala a Deo, Rea y Deméter. Versos de Museo en época de los Pisistrátidas: Hdt., VII, 6; Himno a Deméter para los Licómidas: Paus., I, 22, 7. Temístocles reconstruye el Telesterion de Flia tras la desvastación de los persas: Plut., Them., 1, 4.

60 A. Bernabé (1999), p. 333. L. Brisson (1985), p. 410-411. Ver, sin embargo, A. Bernabé (2002) que señala cómo la alusión a ciertos elementos del mito o del rito implica necesariamente la existencia de otros.

1 O. KeRn, fr. 49 sq., cf. Orph. Test. 221 Kern (Marmor Parium, FGrH 239 A 14). En el himno homérico también se narra el rapto de Perséfone por Hades, pero no la unión de Deméter y Zeus, que sí aparece en Hesíodo (Hes., Th., 912-913).

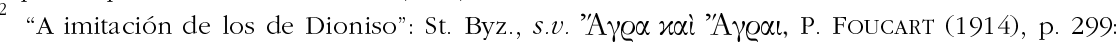
interpreta mimema como representaciones de la historia de Dioniso, del mismo modo que en los Misterios de Eleusis se reproducía el rapto de Core. Para otras interpretaciones: M.H. JAMESON (1965), p. 159-162; este autor rechaza la presencia de Dioniso y relaciona los Pequeños Misterios 
comer y beber "en el tambor y en el címbalo" que recuerda o evoca tanto los Misterios de la Madre, como los de los Curetes o Coribantes (asociados a la Madre $)^{63}$, y sobre todo, en este contexto, el mito de los Titanes que descuartizan a Dioniso y lo consumen, permite dar una coherencia a todo el texto que aludiría, en efecto, a una secuencia iniciática órfica acompañada por relatos y acciones rituales concretas en esta fiesta de los Pequeños Misterios.

La existencia de teletai, que representaban el drama sagrado del nacimiento y desmembramiento de Dioniso por parte de los titanes, está documentada en Clemente de Alejandría (quien alude al hecho de que el dios fue cocinado y devorado por ellos: Prot. II, 17, 2) y se confirma con el papiro Gurob del s. III a.C. ${ }^{64}$ Ambas fuentes mencionan a los Curetes que guardaban al niño, vinculados con el mito de Zeus-niño en Creta, escondido para no ser devorado por su padre Crono ${ }^{65}$. La alusión en el escolio de Platón que hemos analizado acerca de la acción ritual de comer y beber en el tímpano y el címbalo remite claramente al culto de los Coribantes y de Méter, y posiblemente también al mito y culto de un niño divino, (Zeus o Dioniso, en torno a los que danzan al son de la música los Coribantes o Curetes). Esto unido al

con Zeus Miliquio. Culto de Zeus Miliquio en Agras: P. Chantraine (1956), p. 1 sq.; G. Daux (1963), p. 624-625.

63 E. Will (1960), p. 100 y 10; R. PARKER (1996), p. 194. Ar., V., 442; Estrabón, X, 3, 13. J.P. GuÉPIN (1968), p. 292 sq. (para la iniciación coribántica asociada a los Pequeños Misterios de Agras y al mito del descuartizamiento de Dioniso por parte de los titanes). Varios autores han relacionado, de hecho, los synthema ("he comido del tímpano...") integrados en el escolio de Platón y recogidos también por Clemente (en el contexto de su narración de los Misterios de Deo: ver nota 67) y por Fírmico Materno (nota 52), con los Misterios de Rea-Cibeles, la diosa frigia y Attis: F. GRAF (1997), 223 y especialmente Ph. BORGEAUD (1998) en conexión con el ritual del Taurobolion instaurado hacia el s. II d.C. Este autor admite, sin embargo, la integración de un bagaje legendario y mítico anterior con conexiones órficas en el relato de Clemente (p. 189-190). Quizá es significativo el hecho de que en Flia en el Ática, por ejemplo, se instale el Taurobolion en un lugar de culto "órfico" donde se veneraba a Gea, Deméter-Rea, Perséfone y Dioniso, probablemente desde el s. VI, como en Agras: I. Loucas, E. Loucas (1986).

64 A. Bernabé (2002), T 21, T 22, p. 415. Para el papiro de Gurob: J. Hordern (2000). Para las Teletai órficas: A. JimÉNEZ SAN CRISTÓBAL (2002).

${ }^{65}$ Curetes en Creta en relación con el sacrificio de niños a Cronos: Istros, FGrH 334 F 48. Curetes iguales a los Dáctilos del Ida: Paus., V, 7, 6. Curetes: Apolodoro, Biblioteca I, 1. Culto de la diosa Madre frigia asociada al niño divino y a los Coribantes: Estrabón, X, 3, 13 sq. Coribantes iguales a los Cabiros en Mesenia: Paus., III, 24, 5; VIII, 37, 6. Cabiros de Beocia en Misterios en los que los protagonistas son un personaje barbado (Kabiros) y su hijo, Pais (similares ambos a Dioniso y especialmente a Dioniso-Zagreo asociado al toro), fundados según Pausanias por un Licómida de Flia (lugar de culto de Rea-Deméter-Gea, además de Dioniso y Core Protogone, entre otros dioses: ver notas 12 y 47) del Ática: Paus., IV, 1, 7. Restos del Kabirion de Tebas desde época geométrica: A. SCHACHTER (1985), p. 147. Para el culto mistérico de los Cabiros y la presencia en ellos también de Deméter Cabiria (así como de niños): M. Daumas (1998), especialmente p. 83 (es significativa la importancia de la hierogamia en la fiesta, presente también en las Antesterias y posiblemente en los Pequeños Misterios como podría indicar la alusión al lecho nupcial). Ver W. BuRkERT (1985), p. 261-262, 280 (Curetes y Misterios de la Madre); p. 281282 (Cabiros de Beocia, resaltando las similitudes con las Antesterias atenienses). Para mitos de desmembramiento y cocción en un caldero en relación con las Antesterias: M. VALDÉs (1998). 
hecho de que se está hablando explícitamente en el escolio de los grandes y de los pequeños misterios de Eleusis y se ha mencionado el rapto de Perséfone y la unión de Zeus y de Deméter, lleva a pensar en Dioniso-niño, hijo de Perséfone y de Zeus, custodiado por los Curetes (presentes en los testimonios de Clemente de Alejandría y del Papiro de Gurob) y devorado por los titanes. Tanto Deo (Deméter) como Zeus y Perséfone están mencionados explícitamente en el escolio; a la Madre y a los Curetes o Coribantes se alude sin embargo implícitamente en la referencia al ritual relacionado con los címbalos y tambores, lo que apunta a la celebración de la fiesta en el Metroon de Agras, donde Deméter se identifica con Rea o la Madre. La representación o dramatización de la unión de Zeus con Perséfone y de la muerte de Dioniso

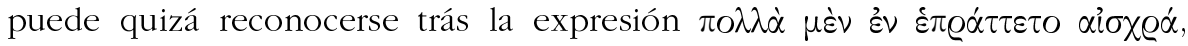
dado que se trataba especialmente de historias secretas, que no se podían contar y que formaban parte de los Misterios báquicos, como señala Bernabé, quien pone de relieve también con énfasis la imbricación entre mito y rito, e. e. entre "relato sagrado" y teletai ${ }^{66}$.

Una confirmación de esta secuencia mítica y ritual, ligada a los Pequeños Misterios de Agras en el escolio de Platón, se halla en el mismo Clemente. En su testimonio se encuentra literalmente parte del escolio (capítulo II, 15, 3) cuando describe los Misterios de Deo (sin hacer referencia en el Protréptico a su vinculación con los Pequeños Misterios citados en el escolio, aunque sí menciona éstos en Stromata $)^{67}$. En dichos misterios se produce la unión de Zeus con Deo o Deméter (Protr. II, 15, 1), como ocurre en nuestro escolio (y en el Papiro de Derveni). A continuación se hace referencia a los Misterios de la Madre y los Coribantes y se retoma el relato sobre los Misterios de Deo con alusión al nacimiento de Perséfone, consecuencia de la unión de Zeus con Deo. Luego se narra el nacimiento de Dioniso y de Zeus en forma de serpiente (Protr. II, 16), y se hace referencia a los misterios de Sabazio, en los

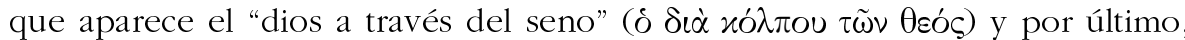
se hace alusión al mito del desmembramiento de Dioniso (Protr. II, 17-18) ${ }^{68}$.

\footnotetext{
${ }_{67}^{66}$ A. Bernabé (2002), p. 413-414.

Strom. V, 11, 71, 1. Misterios de Deo: Prot. II, 15-16. El escoliasta de Platón (posterior a Clemente de Alejandría) toma una parte de la descripción de los Misterios de Clemente de Alejandría o quizá de una fuente común a ambos. En el escolio se liga esta parte, incluida literalmente en la descripción de Clemente (en la que no se especifica a qué misterios concretos se está refiriendo, aunque si se alude a que son los "misterios de Deo"), con los Pequeños Misterios de Agras (ver, sin embargo, para otra interpretación la nota 63). De todas formas es significativo, también en relación con los Pequeños Misterios, que se mezclen o se unan los "Misterios de Deo y los de Rea", o que se intercalen en "los misterios de Deo" (en los que se produce la unión Zeus-Deo, y Zeus-Perséfone), los misterios de Cibeles, dado que los Pequeños Misterios de Eleusis tenían lugar en el Metroon (lugar de culto de Rea o Cibeles). Todo ello podría apuntar a que quizá Clemente de Alejandría en ese pasaje del Protréptico (II, 15 y II, 16) se esté refiriendo con los "Misterios de Deo" a los Pequeños Misterios de Agras.

68 La secuencia ritual (symbola o synthema) que cita Clemente y que se reproduce exactamente en el escolio en relación (creemos) con los Pequeños Misterios de Agras ("bebí en el tambor..."), no es exactamente la misma que la de los propios misterios eleusinos, pero sí muy parecida. La de los Misterios eleusinos se describe un poco más adelante en Clemente, Prot, II,
} 
La hipótesis de una alusión al drama sobre la unión de Zeus con Deo, al nacimiento de Perséfone y Dioniso, y al mito del desmembramiento del dios en los Pequeños Misterios fundados por los Pisistrátidas se refuerza, por otra parte, con la noticia tantas veces mencionada sobre la composición de Onomácrito en la corte de los Pisistrátidas de orgia nuevos para Dioniso. En concreto Pausanias hace referencia a que Onomácrito tomó el nombre de los Titanes de Homero y los hizo artífices de los padecimientos del dios ${ }^{69}$. Tanto la noticia sobre Onomácrito en época de los Pisistrátidas como la fundación de los Pequeños Misterios en época de los tiranos para "iniciar" y "purificar" a Heracles (y a sus seguidores), como muestra el vaso de Reggio, refuerzan la idea de una temprana inauguración de los Pequeños Misterios como unos Misterios "órficos".

Otro indicio de la presencia de Dioniso niño en los Pequeños Misterios es la alusión al liknon en el escolio de Platón (kernon: to liknon), que aparece también en la representación de los Pequeños Misterios en la urna de Lovatelli sobre la cabeza de Heracles ${ }^{70}$.

El liknon es propio también de las Leneas (similares a la celebración en Delfos de Dioniso Liknites) y/o de las Antesterias ${ }^{71}$, fiestas estas últimas que tenían lugar en el mismo mes que los Pequeños Misterios y en las que según Filóstrato se recitaban poemas de Orfeo, como hemos señalado más arriba. Posiblemente en el momento de la constitución, en época de los Pisistrátidas,

21: "Ayuné, bebí el ciceón, cogí del cesto y, después de probarlo, lo deposité en la canasta y de la canasta al cesto" (trad. M.C. ISART). Estos synthema eleusinos junto a los que aparecen en Clemente de Alejandría, los "misterios de Deo" (Protr. II, 15), los cita J. HORDERN en su nueva edición del Papiro de Gurôb (2000, p. 134), a propósito de la secuencia ritual descrita en los mismos en la que aparece también: "as an ass I drank...". La expresión en Clemente (Protr. II,

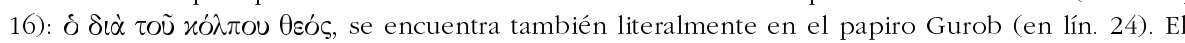
papiro de Gurob alude asimismo a Brimó (megale?), Deméter Rea, los Curetes en armas..., lo que concuerda con el escolio de Platón y con Clemente que mezclan los "misterios de Deo" y los de Cibeles.

69 Paus., VIII, 37, 5.

70 Para la urna Lovatelli y el sarcófago de Torre Nova que aluden a la iniciación y purificación de Heracles en los Pequeños Misterios: G. Mylonas (1961), fig. 83 y 84 . Aunque son de época romana podrían ser una copia de parte de los frisos del Metroon del Iliso de finales del s. V: H. MÖBIUS (1935/6), p. 250; J.P. GuÉPIN (1968), p. 295. Para conexiones purificatorias de esta escena: N.J. RICHARDSON (1974), p. 211 sq.; M. VALDÉs (2004), n. 44 (en relación al Dios koidion); J.P. GUÉPIN (1968), p. 322 sq. Las purificaciones en los pequeños Misterios se realizaban también a través del agua del Iliso y con el sacrificio de cerdos.

71 Dioniso Liknites en Delfos: Plut., Isis y Osiris, 35 (Mor, 465a). Ver nota 21. Liknon en un chous (vaso propio de las Antesterias del día de Choes) donde aparece con la máscara del dios: A. Pickard-Cambridge (1968), fig. 24; G. Van Hoorn (1951), fig. 38; W. Burkert (1983), p. 236-237. Vasos de Leneas: M. VALDÉs (2002a), p. 230, n. 107. El liknon asociado a la máscara de Dioniso se ha ligado al mito del desmembramiento de Dioniso en concreto en la fiesta de las Leneas: R. SEAFORD (1981), p. 267; id. (1994), p. 262, n. 122. Sin embargo el hecho de que el vaso sea un chous propio de las Antesterias, podría aludir más bien a esta fiesta: M. VALDÉs (1998); I. LADARICHARDS (1999), p. 96, que se inclina finalmente por las Leneas; ver W. BURKERT (1983), p. 226. En cualquier caso es posible que este mito del desmembramiento y renacimiento o recomposición de Dioniso sea común tanto a Antesterias (donde se veneraba a Dioniso Leneo), como a las Leneas: M. VALDÉS (1998). 
de los Pequeños Misterios, dedicados a las diosas eleusinas, se tomó parte del fondo mítico y ritual propio de fiestas atenienses consagradas a Dioniso (como Leneas y Antesterias ${ }^{72}$, y en concreto quizá la figura de Dioniso niño y el mito de su desmembramiento ${ }^{73}$ ), y se vinculó a Deméter y Perséfone a través precisamente del desarrollo de ciertas ideas de carácter órfico, que circularían en Atenas por entonces.

Lo nuevo y original, por tanto, que introduce o, más bien, enfatiza Onomácrito en los orgia nuevos de Dioniso que estamos asociando en este artículo con los Pequeños Misterios de Agras, es el vínculo con Perséfone y el protagonismo de los titanes en la muerte del dios, ambos aspectos (nacimiento de Perséfone unida a Zeus y muerte a manos de los titanes) estrechamente relacionados e imbricados en las fuentes y probablemente también en el culto ${ }^{74}$. El papel central de Perséfone en los Pequeños Misterios, especie de "filial" de los Grandes Misterios dedicados a Deméter y Core, pudo haber sido destacado tal vez a causa de la influencia de corrientes "órficas" de Magna Grecia, donde el culto de la diosa era especialmente relevante, dada la presencia de personajes procedentes de Crotona y Heraclea en la corte de los Pisistrátidas $^{75}$. Por otra parte hay que contar también con la actividad en Atenas de Laso de Hermíone, originario de la ciudad del Peloponeso donde existía un culto de Deméter Ctonia y de Persephoneia, que como ha señalado Breglia posiblemente influenció la teogonía de Ferécides de Siro, fechada en el s. VI y a la que los autores antiguos atribuyen la noción del alma eterna ${ }^{76}$.

72 Recitación de poemas de Orfeo en las Antesterias: Filóstrato, VA IV, 21. M. VALDÉs (1998).

73 Para el liknon en relación con el mito de desmembramiento de Dioniso en las Antesterias pero también en los Pequeños Misterios de Agras: J.P. GuÉPIN (1968), p. 288 y 308-310.

${ }^{4}$ Dioniso órfico hijo de Perséfone por primera vez mencionado en fuentes helenísticas: Calímaco, fr. 43, 117 Pf. (Zagreo); Cal., fr. 643 = schol., Lyc. 207 (desmembramiento de Dioniso por los titanes y caldero); véase también Cal., fr. 517 (Et. Gen. = Et. M. 255.14-16; Filócoro, FGrH 328 F 7). Alusión al mito de su muerte a manos de los titanes: Euforión, fr. 13 De Cuenca (14 Groningen): lo echaron a una caldera hirviendo. Ver también: D. S., V, 75, 4 (nacimiento de Perséfone y mito de desmembramiento); schol. Luc., 52, 9 (p. 212ed. Rabe): "Sabazio-Mitra; pues Mitra es entre los Persas igual a Helios. Unos lo llaman Dioniso, nacido de Sémele, otros dicen que es anterior a aquél en el tiempo, nacido de Zeus y Perséfone.... Y dicen que era un impostor y que transformándose en serpiente se unió a su propia hermana". Ver también: Hsch. Suda, Phot., Et. M. s.v. Zagreus; Harpocración, s.v. leuke. Sch. Eur., Troad., 1230: lamento por Iaco muerto, hijo de Perséfone. J.P. GuÉPIN (1968), p. 281. F. Graf (1974), p. 74-75 (para Dioniso como hijo de Perséfone).

M. Di Marco (1993), p. 143. Para los cultos de Magna Grecia en general: G. GianelL (1963). Para orfismo en Magna Grecia: Orfismo, 1975. Relación orfismo y pitagorismo: M. TORTORELli et al. (2000). Culto de Perséfone y laminillas áureas: G. ZunTZ (1971); bibliografía sobre las mismas: A. BERNABÉ (1991), p. 28 sq. Para los documentos recientes relacionados con el orfismo desde un punto de vista crítico: C. CALAME (2002). Es interesante constatar que el vaso de Reggio en el que aparece Heracles como iniciado y se menciona a Plutodotas se encontró en el santuario de Perséfone en Locro: E. SimON (1997), p. 98.

Deméter Ctonia en Hermíone y Climeno (= a Hades): Paus., II, 35, 4-10; III, 14, 5 (asociado a Orfeo y a Hermíone); Str., VIII, 6, 12, p. 373 (Lugar de acceso al mundo subterráneo). Fragmento del himno a Deméter de Laso de Hermíne que cita a Deméter, Core y Climeno, siendo Perséfone la consorte de Climeno: Ateneo, XIV, 624e. En varias inscripciones de 
Paralelamente se produciría, a partir de tradiciones locales de la leyenda eleusina, el inicio del desarrollo de versiones órficas, en las que Triptólemo, asimilado al mismo tiempo como héroe ático del grano y de la cultura con proyección panhelénica, es una de las figuras centrales. Ello encaja perfectamente con su representación en el vaso de Reggio del 540 (en el que aparece también Plutodotas), relacionado con la iniciación de Heracles. Otro vaso de figuras negras de la segunda mitad del s. VI en el que se representa a Triptolemo y a Hermes (también presentes en el vaso de Reggio) muestra a Dioniso por el otro lado $(A B V, 331,13)$. Lo más interesante es la existencia de representaciones en el s. V y IV (p.e. un pelike de Bruselas) en las que se unen en un contexto eleusino junto a Deméter, Core y Triptólemo, Heracles, como prototipo de mystes (iniciado en los Pequeños Misterios previa participación en Eleusis), y Dioniso.

Feytman se pregunta cuál es el nexo de unión entre Heracles y Dioniso y concluye que hay uno: los Misterios de Eleusis. Nosotros podríamos entrar aún más en detalle y señalar que la presencia de Dioniso en los vasos, en los que se muestra a Heracles como mystes en un contexto eleusino (en el que se halla igualmente representado Triptólemo), puede deberse más que a la importancia de Dioniso en los Misterios de Eleusis (que no es tan acusada en un primer momento y se centra sobre todo en la figura de Iaco), al hecho de su posible protagonismo en los Pequeños Misterios de Agras, fundados precisamente para poder iniciar, previa purificación, a Heracles en los Misterios eleusinos ${ }^{77}$.

Hermíone: IG IV, 685-692 (Deméter, Climeno y Core). Laso: G.A. PRIVITERA (1965). Importancia del culto de Core ligada a Deméter y Hades en Hermíone ya desde Laso estrechamente vinculado igualmente con Atenas: L. BREglia (1997). Según Breglia (2000) tanto el culto de Deméter Ctonia y Perséfone en Hermíone como el de Perséfone en Sicilia pudieron influenciar la teogonía de Ferécides en la que Ctonia se une a Zas y se transforma en Ge. Esta autora señala los rasgos de Perséfone también como "diosa madre" en Locro y en las laminillas órficas (p. 190). Breglia pone de relieve asimismo, con acierto, que grupos ligados a Onomácrito han valorado el tema de la autoctonía en Atenas y la descendencia de la Tierra (p. 190); este comentario nos parece especialmente relevante porque, en efecto, el nacimiento de Dioniso de Perséfone en estos momentos (s. VI) podría ser paralelo al desarrollo también en el s. VI del mito de otro nacimiento, el de Erictonio, hijo de Hefesto y Gea (a partir de Erecteo hijo de la tierra ya en Homero). Ferécides presenta una concepción filosófica avanzada para su época, que lo pone en contacto con Pitágoras (según algunas fuentes, su maestro) y según Cicerón (Cic., Tusculanae disputationes I, 16, 38 = Pher. Syr., fr. 7 Schibli = A 5 D-K) fue el primero en decir que las almas de los hombres eran eternas, lo cual lo convertirá en predecesor de las ideas órficas sobre el alma. Sobre los elementos cosmogónicos primordiales, Zas, Ctonia y Tiempo en Ferécides: R.B. MARTínEZ NiETO (2000), p. 92-110.

77 Triptolemo y versión órfica de la leyenda eleusina: M. VALDÉs (2004). Ver más arriba nota 25 para Triptólemo. Para el vaso de Reggio: ver nota 29. J.D. BEAZLey, $A B V$ 331, 13 (A: Dioniso en carro alado; B: Triptólemo y Hermes). Pelike de Bruselas R. 235: D. FEyTMAN (1945), especialmente p. 307-314 (otro vaso de mediados del s. V, el skyphos A 10 de Bruselas muestra la iniciación de Heracles en Eleusis, Triptolemo y Dioniso). Este vínculo fue puesto de relieve en relación con los Pequeños Misterios por E. SimON (1966), p. 84, n. 74. Pequeños Misterios en relación con la iniciación de Heracles: ver nota 78 . 
En el contexto de las relaciones entre Atenas y Eleusis iniciadas ya desde antes de los Pisistrátidas ${ }^{78}$ se entiende la inclusión de elementos dionisíacos en los Misterios (como Iaco, el canto o grito de invocación al dios niño de las Leneas que se convierte en el grito ritual propio de los mystai), y de elementos del culto eleusino en fiestas dionisíacas como las Leneas (presencia del daduco invocando al dios llamado Plutodotas: "Iaco, hijo de Sémele Plutodotas") $)^{79}$.

Las fuentes sobre los Pequeños Misterios de Agras señalan, en efecto, que fueron fundados por Deméter para poder iniciar a Heracles en los Misterios de Eleusis $^{80}$. Una clara alusión a esta tradición se descubre en la obra de Aristófanes, Ranas, en las que Dioniso acude a Heracles (posiblemente en su santuario del Cinosarges junto al Iliso ${ }^{81}$ ) para preguntarle por el camino al Hades. Lada-Richardson ha visto en esta obra, en los versos 473-8, una posible alusión al mito del desmembramiento de Dioniso (en este caso Dioniso disfrazado de Heracles a las puertas del Hades, después de haber encontrado al cortejo de los mystai conducidos por Iaco), que asocia con fiestas como Leneas y Antesterias ${ }^{82}$. Dada la alusión en la obra a la iniciación de Heracles, y las referencias a la topografía del Iliso, podría verse también detrás de esta posible alusión al desmembramiento de Dioniso, una tradición de la fiesta de los Pequeños Misterios de Agras, que habría incorporado este mito reelaborado por Onomácrito.

Por último, la presencia en el vaso de Reggio de Plutodotas ${ }^{83}$ junto a Triptólemo (y en conexión con el mito de la iniciación de Heracles y de su aventura en el Hades), podría asociar la imagen de este vaso con los Pequeños Misterios, y con el protagonismo de Zeus en ellos, tanto por su unión con Deméter (citada en el escolio de Platón y en el papiro de Derveni), como en su hipotética unión con Perséfone celebrada en la fiesta.

En definitiva Zeus Rey (Basileus), como indica la presencia del cetro y la majestad de la figura en el vaso, que aparece también en el himno de finales

78 D. PlácIdo - M. VAldÉs (1998).

79 Sch. Ar., Ra., 489. Para Iaco: M. VAldés (2004), ver el apéndice. En Miconos se realizaban en el mes Leneo sacrificios en honor de Deméter, Core, Zeus Bouleo (el diez), de Sémele (el once), y de Dioniso Leneo, Zeus Ctonio y Gea Ctonia (el doce): LSCG: F. Sokolowski (1969), no 96, lín., 15 sq.; A. Pickard-Cambridge (1968), p. 36.

Diodoro Sículo, IV, 14, 3. En esta versión, iniciado por Museo, aunque posiblemente en origen fuera más bien Triptólemo el que lo inicia como aparece en el discurso de Calias en Jenofonte (Xen., Hell. VI, 3, 6). Para la purificación de Heracles en relación con los Pequeños Misterios: sch., Ar., Pl., 846, 1014; Ps. Platón, Ax., 371e; Polyaen, Strat. V, 17, 1; L. DeubNER (1932), p. 70

G. HOOKER (1960).

82 I. LADA-RICHARDS (1999), p. 95.

83 Plutodotas referido a Iaco en las Leneas: Sch. Ar., Ra., 479. En un himno órfico Zeus es llamado Miliquio y Plutodotas: ver nota 30. Connotaciones órficas del epíteto: H.A. SHAPIRO (1989), p. 79-80. 
del s. VI recogido en el papiro ${ }^{84}$, tiene en su versión ctónica, como Miliquio, una especial relevancia en esta zona de Agras junto al Iliso, donde se celebraban las Diasias (también en Antesterión) en honor del dios, al menos desde el s. VII ${ }^{85}$. Este dios se asocia asimismo con el ritual purificatorio del Dios koidion (Sud. s.v.), utilizado por el daduco y por otros (con las pieles de los animales sacrificados a Zeus Miliquio y Ktesio $^{86}$ ) y que aparece representado en la urna y en el sarcófago de época romana (tal vez copia de los frisos del templo del Iliso $^{87}$ ), asociados con la celebración de los pequeños misterios. La mención de Plutodotas en el vaso de 540/30 puede estar aludiendo ya, por tanto, a la presencia destacada de Zeus (Miliquio), confundido o identificado con Hades en un fragmento de Eurípides ${ }^{88}$ en el que se alude también al cetro del dios, quien se uniría en primer lugar con Deméter (como señala el escolio de Platón sobre los Pequeños Misterios) y a continuación con Perséfone ${ }^{89}$ para engendrar de ésta a Dioniso. Precisamente el Zeus que se une a Perséfone en los textos órficos, es un Zeus ctónico identificado con una serpiente ${ }^{90}$, símbolo también de Zeus Miliquio en diversos relieves áticos de los s. IV/III, donde se representa igualmente al dios con el cuerno de la abundancia (y con el cetro) ${ }^{91}$.

Por último, otro probable indicio del protagonismo del dios (junto a Méter/Deméter y Perséfone) en los Pequeños Misterios es el hecho de la aparición entre los relieves votivos hallados en las cercanías del Metroon, de uno en el que se encuentra al dios (Zeus ctónico) recibiendo a Heracles y Hermes. Esta muestra recoge de nuevo, por tanto, varios de los personajes que aparecen en el vaso de Reggio del 540 a.C: Heracles y Hermes y quizá Plutodotas que podría ser identificado en el vaso de Reggio por las caracterís-

84 M.L. West (1983), p. 114-115 (Basileus: lin., 5, 29; cetro: lin., 7). A. BernABÉ (1999), p. 327. Zeus igualado a Hades portador de cetro: Eur., fr., 912 Nauck. Zeus Basileus citado ya por Solón, fr. $28 \mathrm{D}$.

${ }^{85}$ Th., I, 126, 6. Ver más arriba para el himno órfico en el que se alude a Zeus como Miliquio y Plutodotas: nota 30. Diasias: M.H. JAMESOn (1965). Zeus Miliquio: N. Cusumano (1991). Culto de Zeus en Atenas arcaica: M. VALDÉs (2002c).

Zeus Ktesios es llamado también Plutodotas: Sud., s.v. Para purificaciones en relación con la exégesis en Atenas: M. VALDÉs (2002b).

${ }^{87}$ Ver más arriba nota 68.

${ }^{88}$ Fr. 912 Nauck = Clem. Al., Strom. V, 688

89 En Clemente de Alejandría que alude a la continuación de la historia: Protr. II, 15-16.

90 Clem. Al., Protr. II, 16, 1; Arnobio, Nat. V, 21; ver más arriba también el escolio a Luciano: nota 74. J.P. GUÉPIN (1968), p. 295; M.L. WEST (1983), p. 95. Zeus aparece con el epíteto Ctonio junto a Deméter en relación con la agricultura en Hesíodo (Hes., Op., 565 sq.) y junto a Perséfone como Katachtonios en Homero: Hom.., Il., 9.457, citado por Pausanias (Paus. II, 24, 4) que alude al xoanon excepcional con tres ojos y su carácter de arcaico símbolo de omnisciencia, $c f$. J.G. FrAZER II, p. 209 y R. PETTAZZONi (1957), p. 27 sq. Sobre la triplicidad de Zeus, señor de las tres partes del mundo, $c f$. Esquilo, Suppl., 155; HO, 63, 16; Sch. Eur., Troad., 16; T.P. Howe (1955).

91 M.H. JAMESON et al. (1993), p. 94. N. CUSUMANO (1991), p. 26-27. 
ticas con las que se presenta (hombre maduro, con barba y cetro) con el mencionado Zeus ctónico. ${ }^{92}$

En el mismo himno órfico en el que se alude a Zeus como Plutodotas se hace referencia al dios como Miliquio. Ambos epítetos están documentados en Atenas arcaica, el primero en el vaso de Reggio del 540, y el segundo en la fiesta de las Diasias que menciona Tucídides a propósito del atentado ciloneo en el s. VII, y que al parecer era venerado precisamente en la zona de Agras ${ }^{93}$.

En este sentido no es probablemente una casualidad que el mismo Laso de Hermíone que compone un himno para Deméter y que está implicado, con Onomácrito, en la literatura "órfica" y en la atribuida a Museo en esos momentos, se encuentre estrechamente vinculado en la Atenas del s. VI con la familia de los Bouzygai cuyo primer miembro conocido es Ariphron, abuelo de Pericles y asociado a Pisístrato por las fuentes ${ }^{94}$. Los Bouzygai realizaban, como el daduco, purificaciones y estaban a cargo del culto a Zeus Teleios y posiblemente Miliquio en la zona del Iliso ${ }^{95}$. Es ciertamente indicativo que Laso de Hermíone, el mismo personaje con conexiones órficas, al igual que Onomácrito, que se encarga de hacer un himno a Deméter, se halle al mismo tiempo ligado al culto de Zeus del Iliso, con caracteres ctónicos representado en Atenas como Philios, Teleios, Miliquio, al menos posteriormente en el s. IV, en forma de serpiente ${ }^{96}$.

\section{Epílogo}

La posibilidad de que los Pequeños Misterios de Agras fueran unos misterios órficos o con componentes órficos (como el nacimiento de DionisoZagreo y su muerte a manos de los titanes) fue postulada ya hace tiempo por Simon y Guépin, la primera lo hace a partir del análisis iconográfico de un vaso del s. IV a.C. y el segundo basándose sobre todo en relación con los

92 H. MÖBIUS (1935), p. 247 sq. (P1. 90 y 91). K. KERÉNYI (1967), p. 51, fig., 10. J.P. GUÉPIN (1968), p. 282-283: supone que la consorte que acompaña a Zeus Miliquio es Perséfone en lugar de Méter, como había supuesto H. MÖBIUs; J.P. GuÉPIN (1968) interpreta un vaso del 420 de Spina (J.D. BEAZley, $A R V^{2}$, p. 1052, no 25: interpretado por este autor como Sabazio y Cibeles) como la representación de Zeus ctónico coronado con una diadema con serpientes y sosteniendo también un cetro y la fíala de Plutón, acompañado de su consorte que identifica como Perséfone (junto a un león): pp. 209-310.

93 Himno órfico: G. Ricciardelli (2000), no 73. Iniciación de Heracles en relación con la inauguración de los Pequeños Misterios de Eleusis: : nota 80. Diasias: Th., 1, 126, 6.

94 P.Oxy. IV, 664 (diálogo entre Arifrón y Pisístrato sobre la tiranía de Periandro): B.P. Grenfell, A.S. Hunt, The Oxyrhynchus Papyri 4, London, 1904, p. 72-80; P.Oxy. L, 3544 (The Oxyrbynchus Papyri 50, Oxford, 1983, p. 93-99). Relación de Jantipo con Anacreonte que formó parte de la corte de los Pisistrátidas: Himerio, Orationes, 39, 11 p. 159 sq. Colonna (ed. PAGE, $P M G, 229$, fr., 493: "Anacreonte saluda al "gran" Jantipo en la corte del tirano Polícrates"). Estatuas de Jantipo y Anacreonte juntas en la Acrópolis: Paus, I, 25, 1. Anacreonte en la corte de los Pisistrátidas: P1., Hipparch., 228b-c.

95 M. VALDÉs (2002b, 2002c).

96 En el mito órfico Zeus después de unirse a Deméter se une a Perséfone en forma de serpiente: Clem. Al., Protr. II, 16, 1; Arnob., Adv. Nat. V, 21. 
descubrimientos del supuesto Metroon de Agras en el Iliso del s. V y con los desarrollos cultuales y míticos de Atenas en el s. V. Con este artículo hemos pretendido retomar una hipótesis largo tiempo olvidada, ignorada o desechada, fundamentándola en los desarrollos religiosos, culturales e históricos propios del s. VI. Entre ellos destacan el culto a la Madre y su identificación con Deméter y Gea en la Atenas de esos momentos, el culto de Zeus Miliquio en Agras desde el s. VII al menos y la preeminencia de Zeus Basileus ya desde Solón.

Por otra parte, se comprende también en el contexto histórico de la Atenas de los Pisistrátidas la necesidad de establecer unos Misterios "purificatorios" para justificar la apertura de los Misterios de Eleusis a parte de la población, en esos momentos de ampliación de la ciudadanía; además, contamos con las noticias de la presencia de personajes con conexiones órficas en Atenas en estas fechas. Es posible que en estos momentos (a partir de Solón), de integración y consolidación de los Misterios eleusinos en Atenas, se produjera la inclusión de elementos dionisíacos (como Iaco) en los Misterios eleusinos y viceversa (el daduco y el hierocérice en Leneas y Antesterias) ${ }^{97}$. El s. VI es el momento en el que supuestamente Onomácrito compuso orgia nuevos para Dioniso (cuyo contenido central era su muerte a manos de los titanes) en la ciudad de Atenas. En este mismo siglo se atribuye a los tiranos la inauguración de los Pequeños Misterios en Agras "para iniciar a Heracles en los Misterios", como parece atestiguar el vaso de Reggio ${ }^{98}$.

La hipótesis del vínculo de estos orgia con los Pequeños Misterios se fundamenta en lo que parece ser el contenido de los mismos que hemos tratado de discernir a partir de fuentes diversas; en los Misterios de Agras ocupan un lugar especial la diosa Perséfone, el relato sobre la unión de Zeus con Deméter, los ritos orgiásticos similares a los de los Curetes, los Coribantes y la Madre de los dioses, en cuyo templo, en Agras, se celebrarían los Misterios, y Dioniso, mencionado por Estéfano de Bizancio, vinculado al liknon en el ritual y a los Curetes en el mito órfico.

Si podemos concluir que los Pequeños Misterios son unos Misterios órficos instituidos en época de los Pisistrátidas, entonces habría que volver a examinar al menos algunas de las interpretaciones de los distintos autores sobre la introducción del orfismo con los Pisistrátidas. Nilsson destacó la relación estrecha entre dionisismo y orfismo señalando sin embargo, precisa-

97 Sch. Ar., Ra., 479; D., (59) Neera, 73-78. Ver apéndice de: M. VALDÉs (2000 en prensa).

98 E. SIMON (1966); esta autora se centra fundamentalmente en el análisis del Pelike de Leningrado (St. 1792) del s. IV, aunque alude también someramente a la posibilidad del desarrollo de los Pequeños Misterios como unos misterios órficos en época de los Pisistrátidas, en relación con la noticia sobre Onomácrito: p. 84. J.P. GuÉPIN (1968, esp. p. 280 sq.) defiende tanto las similitudes de las Antesterias con los Pequeños Misterios, como la presencia de Dioniso órfico en éstos (aunque menciona también a Onomácrito y los Pisistrátidas, y se centra en el análisis de los mitos y ritos en la tragedia griega en el s. V). Para el vaso de Reggio véase la nota 29. Culto de Heracles en el Ática en el s. VI, especialmente en su santuario del Cinosarges junto al Iliso: S. WOOdFORD (1971); A. Verbanck-PiÉrard (1992), p. 195. Para Heracles en los Pequeños Misterios: J. BOARDMAN (1975); M. VALDÉS (2004). 
mente en relación con la Atenas de los Pisistrátidas, la diferenciación y reinterpretación nueva, aunque arraigada en creencias y "movimientos" populares, del dionisismo operada dentro el orfismo y que conlleva una visión antropológica, escatológica y religiosa relativamente nueva. Mazzarino, por su parte destacó el vínculo del orfismo en estos momentos con la ideología de la basileia acorde con el desarrollo del poder tiránico. Thomson ${ }^{99}$ postuló una mayor relación del nacimiento del orfismo en la Atenas del s. VI con elementos de población humildes, especialmente mineros (en Laurion y Tracia, asociados con los Pisistrátidas) y la relación, sobre todo en su origen, con una ideología "popular", contraria a la mentalidad y el pensamiento "disgregante" aristocrático. Di Marco ${ }^{100}$, por su parte, ha destacado recientemente más bien las conexiones del orfismo con la polis, la religión cívica, del mismo modo que el culto de Dioniso, y señala la posibilidad de una gradual diferenciación entre dionisismo y orfismo desde los Pisistrátidas. Probablemente unos aspectos no son excluyentes de otros, dada la complejidad de la realidad social.

Es posible suponer también la presencia de elementos procedentes de Magna Grecia, así como la influencia, subrayada en este artículo, de la diosa frigia, y otras conexiones externas tanto en elementos de población (los vasos nos ofrecen representaciones de escitas y tracios), algunos tal vez en la guardia del tirano, (formada en su mayoría por atenienses de las clases bajas, como ha mostrado Lavelle), como en cuestión de ideas religiosas. ${ }^{101}$

En cualquier caso el aspecto más relevante a destacar es el hecho de la inauguración de los Pequeños Misterios (unos misterios órficos, con las consecuencias que ello conlleva a la hora de vicular orfismo con ritual, y orfismo con religión cívica) para "iniciar" a Heracles, "el portador de la maza". Ello posibilita, de forma simbólica (y puede suponerse que también en la práctica), la iniciación del demos que sigue y apoya al tirano; e. e. poblaciones marginales y heterodoxas, extranjeros, descontentos, sin tierras, thetes y otros elementos que se integran posiblemente en estos momentos en la ciudadanía de Atenas, como muestra el diapsephismos previo a Clístenes para excluir a los "impuros" y la introducción de "esclavos metecos" en la ciudadanía $^{102}$. Además hay otros elementos que merece la pena destacar como la relación fundamental que se establece ya en estos momentos tanto entre orfismo y dionisismo, como entre orfismo y misterios eleusinos en el Ática.

Sin negar tampoco la importancia del desarrollo de la ideología de la basileia conectada al poder tiránico, como muestra el culto de Zeus

\footnotetext{
99 M.P. NilsSON (1935); S. MAZZARINO (1966), p. 33-34. G. THOMSON (1972)

100 M. Di MARCo (1993): con discusión y bibliografía acerca de las distintas interpretaciones sobre el origen del orfismo y la relación con el culto de Dioniso.

101 Tracios y escitas en los vasos: H.A. SHAPIRO (1983b); B.M. LAVELLE (1992)

102 M. VALDÉs (2004). Diapsephismos: Arist., Ath., 13, 5 y 203. "Esclavos metecos" en la ciudadanía con Clístenes: Arist., Pol. III, 1275b 32-37.
} 
Basileus $^{103}$, es esencial para la comprensión de la inauguración de estos Misterios ligados a la purificación en la Atenas de los Pisistrátidas, el reconocimiento de una promoción del demos. Se abre así al pueblo el acceso a la ciudadanía, al menos en la participación más activa en festivales esenciales para la vida cívica de Atenas, y al Más Allá bienaventurado en los Misterios de Eleusis, a los que se accedía por la participación previa en los de Agras.

Sin embargo no hay que olvidar que la actuación de Onomácrito no es la única que puede conectarse con corrientes "órficas" o relacionadas con orfismo; también otras familias atenienses como los Licómidas y los aristocráticos Bouzygai, posiblemente asociados con Laso de Hermíone con conexiones también con textos órficos y el primero en identificar a Bouzyges con Epiménides, se arrogan esta prerrogativa ${ }^{104}$. El enfrentamiento entre Laso y Onomácrito muestra por tanto también el talante ambiguo del orfismo, que se deja aprehender mal, dada la ausencia de una "ortodoxia" ya desde estos primeros momentos en los que quizá se está formando (s. VI) y en los que se advierte la complejidad del fenómeno religioso denominado "orfismo" en la Antigüedad.

\section{Miriam VALDÉs GứA ROXana MARTíNEZ NIETO}

Unv. Complutense de Madrid

Dpto. de Historia Antigua / Dpto de Filologia Griega

Facultad de Geografia e Historia / Facultad de Filologia

Ciudad Universitaria, $\mathrm{S} / \mathrm{N}$

E - 28040 MADRID

\section{Bibliografia}

A. ALONI, L'aedo e i tiranni, Roma, 1989.

A. BARIGAZZI, "Onomacrito e il primo inno omerico a Dioniso", RFIC 91 (1963), p. 338-340.

J.D. BEAZLEY, Attic Red-Figure Vase-Painters (ARV), Oxford, $1963^{2}$, vol., I y II

-, Paralipomena. Additions to Attic Balck-Figure Vase-Painters, Oxford, $1971^{2}$.

-, Attic Black-Figure vase-Painters (ABV), New York, 1978.

A. BERNABÉ, "La poesía órfica. Un capítulo reencontrado de la literatura griega", Tempus 0 (1992), p. 5-41.

—, "La Teogonía órfica del Papiro de Derveni", ARYS 2 (1999), p. 301-338.

—, "La Toile de Pénélope : a-t-il existé un mythe orphique sur Dionysos et les Titans ? ", RHR 219, fasc. 4 (2002), p. 401-433.

J. BOARDMAN, "Herakles, Peisistratos and Sons", RA 65 (1972), p. 57-72.

—, "Herakles, Peisistratos and Eleusis", JHS 95 (1975), p. 1-12

103 Ideología de la basileia en relación con los tiranos: H.A. SHAPIRO (1983). De todas formas no era exclusivo ni prerrogativa de los tiranos como muestra el vínculo de Solón (fr. 28 D) con Zeus Basileus, así como el desarrollo de Zeus relacionado con la justicia ya desde Homero y Hesíodo. Sobre la Justicia de Zeus: H. LlOYD-JONEs (1971).

104 Laso y Bouzygai en la Atenas de los Pisistrátidas: M. VAldés (2002b), p. 127-128. 
—, "Herakles, Peisistratos, and the Unconvinced", JHS 109 (1989), p. 158-159.

R. BOEHME, Der Lykomide. Tradition und Wandel zwischen Orpheus und Homer, Bern / Stuttgart, 1991.

Ph. Borgeaud, La Mère des dieux, Paris, 1996.

-, "Taurobolion ", in F. GRAF (ed.), Ansichten griechischer Rituale für Walter Burkert, Stuttgart / Leipzig, 1998, p. 183-198

P. Boyancé, Le culte des Muses chez les philosophes grecs. Études d'bistoire et de psychologie religieuses, Paris, $1993^{2}$ [1936].

L. Breglia, "Falce di Demetra, falce per Demetra", in N.F. PARISE (ed.), Origine della moneta e teoria del sacrificio. Atti dell'incontro di studio, Roma 1995, Roma, 1997, p. 43-69.

-, "Ferecide di Siro tra orfici e pitagorici", in M. TORTORElli Ghidini, A. Storchi Marino y A. VisCONTI (2000), p. 161-194.

L. Brisson, "Les théogonies Orphiques et le papyrus de Derveni : notes critiques", RHR 202 (1985), p. 389-420.

A.C. BRumfield, The Attic Festivals of Demeter and their Relation to the Agricultural Year, New York, 1981

W. BURKERT, Orphism and Bacchic mysteries. New evidence and old problems of interpretation, Berkeley, 1977.

-, Homo Necans. The Anthropology of Ancient Greek Sacrifical Ritual and Myth, Berkeley et al., 1983.

-, Greek Religion. Archaic and Classical, Oxford, 1985.

C. CAlame, "La poésie attribuée à Orphée : qu'est-ce qui est orphique dans les Orphica ?", RHR 219, fasc. 4 (2002), p. 385-400.

F. CASSOLA, Inni Omerici, Roma, 1975.

G. CERRI, "La Madre degli Dei nell'Elena de Euripide: tragedia e rituale", QS 18 (1983), p. 155-183.

P. Chantraine, "Metros en Agras", CEM 17 (1956), p. 1-4.

K. Cunton, Myth and Cult. The Iconography of the Eleusinian Mysteries, Stockholm, 1992.

-, "The Eleusinian Mysteries and Panhellenism in Democratic Athens", in W.D.E. Coulson et al. (eds.), The Archaeology of Athens and Attica under the Democracy, Oxford, 1994, p. 161172 .

D.M. Cosi, "Orfeo e l'Orfismo tra continuità e innovazione", in M. TORTORELli GHIDINI, A. STORCHI MARINO, A. VISCONTI (2000), p. 139-159.

N. Cusumano, "Zeus Meilichios", Mythos 3 (1991), p. 19-47.

M. DARAKI, Dionysos, Paris, 1985.

M. Daumas, Cabiriaca. Recherches sur l'iconographie du culte des Cabires, Paris, 1998.

G. DAUX, "La grande Démarchie : un nouveau calendrier sacrificiel d'Attique (Erchia)", BCH 87 (1963), p. 603-634

J.K. DAviES, Athenian Propertied Families, Oxford, 1971.

L. Deubner., Attische Feste, Berlin, 1932.

M. Di Marco, "Dioniso ed Orfeo nelle Bassaridi di Eschilo", in A. Masaracchia (ed.), Orfeo et l'orfismo. Atti del Seminario Nazionale, Roma-Perugia, 1985-1991, Roma, 1993, p. 101-153.

B.C. DIETRICH, "Dionysos Liknites", CQ 8 (1958), p. 244-248.

A.J. Domínguez Monedero, Solón de Atenas, Barcelona, 2001.

R.G. EDMONDS, "Tearing Apart the Zagreus Myth: A Few Diparaging Remarks on Orphism and Original Sin", ClAnt, 18 (1999), p. 35-73.

E.R. FARNELL, The Cults of the Greek States, New York, 1977 [1896-1909], (5 vols.).

D. FEYTMAn, "Une representation inusitée du départ de Triptolème", AC 14 (1945), p. 285-318.

A.J. Festugière, "Les mystères de Dionysos", RBi (1935), p. 366-396.

P. FOUCART, Les mystères d'Eleusis, Paris, 1914.

N. Frapicini, "L'arrivo di Cibele in Attica", PP 42 (1987), p. 12-26.

J.G. FraZER, Pausania's Description of Greece, London / New York, 1898 
G. GianeluI, Culti e miti della Magna Grecia, Firenze, 1963.

F. GRAF, Eleusis und die orphische Dichtung Athens, Berlin, New-York, 1974.

-, "The Arrival of Cybele in the Greek East", in J. HARmatTa (ed.), Actes du VII Congrès de la Fédération Internationale des Associations d'Études Classiques (Proceedings of the VIIth Congress of the International Federation of the Societies of Classical Studies), Budapest, 1984, vol., I, p. 117-120.

- Nordionische Kulte, Roma, 1985.

-, "I culti misterici", in S. SETTIS (ed.), I Greci. Storia, cultura, arte e società. 2. Una Storia Greca. II. Definizione, Torino, 1997, 309-343.

J.P. GuÉPIn, The Tragic Paradox. Myth and Ritual in Greek Tragedy, Amsterdam, 1968.

W.K.C. GUTHRIE, Orfeo y la religion griega, Buenos Aires, 1970 [1934].

B. Hemberg, Die Kabiren, Uppsala, 1950.

G.T.W. HOOKER, "The Topography of the Frogs", JHS 80 (1960), p. 112-117.

G. VAN HOORN, Choes and Anthesteria, Leiden, 1951.

J. HORDERN, "Notes on the Orphic Papyrus from Gurob (P. Gurôb 1; Pack2 2464)", ZPE 129 (2000), p. 131-140.

T.P. Howe, "Zeus Herkeios", AJA 59 (1955), p. 287-288.

J. HuMBERT, Homère, Hymnes, Paris, 1936.

M.H. JAMESON, "Notes on the Sacrificial Calendar form Erchia", BCH 89 (1965), p. 154-172.

M.H. JAMESON, D.R. JoRDAN, R.D. KoTANSKY, A Lex Sacra from Selinous, Durham, 1993.

A.I. JIMÉNEZ SAN CRISTOBAL, "Consideraciones sobre las Teletai órficas", in J.F. GONZÁlez CASTRO, J.L. Vidal (eds.), Actas del X Congreso Español de Estudios Clásicos, Madrid, 2002, vol., III, p. 127-133.

K. KERÉNYI, Eleusis. Archetypal Image of Mother and Daughter, London, 1967.

O. KERN, Orphicorum Fragmenta, Berlin, $1963^{2}$ [1922].

I. LADA-RICHARDS, Initiating Dionysus. Ritual and Theatre in Aristophanes' Frogs, Oxford, 1999.

J. DE LA GENiÈRE, "De la Phrygie à Locres Épizéphyrienne", MEFRA 97 (1985), p. 593-718.

—, "Le culte de la Mère des dieux dans le Péloponnèse", CRAI (1986), p. 29-48.

-, "Statuaire archaïque de la Mère des dieux en Arcadie et en Laconie", in O. PaLAGIA, W. COulson (eds.), Sculpture from Arcadia and Laconia, 1993, Oxford, p. 153-158.

B.M. LAVELLE, "Herodotos, Skythian Archers, and the doryphoroi of the Peisistratids", Klio 74 (1992), p. 78-97.

L.M. L'HOMME-WÉRY, "La notion de patrie dans la pensée politique de Solon", AC 69 (2000), p. 2141.

E. Loucas, I., LOUcas, "Un autel de Rhéa-Cybèle et la grande déesse de Phlya", Latomus 45 (1986), p. 392-404

I. LOUCAS, "Le daphnephoreion de Phlya, la daphnéphorie béotienne et l'oracle de Delphes", Kernos 3 (1990), p. 211-218.

H. LLOYD-JONES, "Heracles at Eleusis", MAIA 19 (1967), 206-29.

—, The Justice of Zeus, Berkeley, Los Angeles, London, 1971.

L. MALten, "Altorphische Demetersage", $A R W 12$ (1909), p. 417-446.

R. MARTIN, Recherches sur l'agora grecque, Paris, 1951.

R.P. MARTIN, "Rhapsodizing Orpheus", Kernos 11 (2001), p. 23-33.

R.B. MARTÍnEZ NiETO, La aurora del pensamiento griego. Las cosmogonías prefilosóficas de Hesiodo, Alcmán, Epiménides, Museo y la Teogonía órfica antigua, Madrid, 2000.

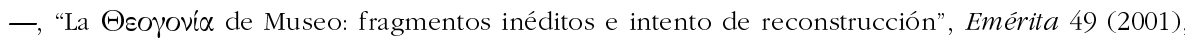
fasc., 1 (primer semestre), p. 115-152.

S.B. MATHESON, "The Mission of Triptolemus and the Politics of Athens", GRBS 35 (1994), p. $345-$ 372.

S. MAZZARINo, Il pensiero storico classico, vol. I, Bari, 1966.

H. METZGER, Recherches sur l'imagerie athénienne, Paris, 1965. 
H. MÖBIUS, "Das Metroon in Agrai und sein Fries", AM 60/61 (1935/6), p. 234-268.

G. MYLONAS, Eleusis and the Eleusinian Mysteries, Princeton, 1961

F. NAumann, Die Ikonographie der Kybele in der phrygischen und der griechischen Kunst, Tübingnen, 1983

M.P. NiLSSON, "Early Orphism and Kindred Religious Movements", HThR 28 (1935), p. 181-230.

Orfismo in Magna Grecia, Atti del XIV Convegno di Studi sulla Magna Grecia, Taranto 6-10 ott., 1974, Napoli, 1975

R. PARKER, Athenian Religion: A History, Oxford, 1996.

R. PETTAZzoni, L'essere supreme nelle religioni primitive, Torino, 1957.

A. Pickard-CAmBridge, The Dramatic Festivals of Athens, Oxford, 1968 ( $1^{\text {a }}$ edición de 1953).

C.A. PICón, "The Ilisson Temple reconsidered", AJA 82(1978), p. $42-81$.

M. PIÉRART, "Héros fondateurs. Héros civilisateurs. La rivalité entre Argos et Athènes vue par Pausanias", in V. Pirenne-Delforge, E. SuÁREZ DE la TORRE (eds.), Héros et héroïnes dans les mythes et les cultes grecs. Actes du Colloque organisé à l'Université de Valladolid du 26 au 29 mai 1999, Liège, 2000 (Kernos, suppl. 10), p. 409-434.

D. Plácido, "Cresmólogos, adivinos y filósofos en la Atenas clásica", in J. Alvar, C. BlánQUEZ, C.G. WAGNER (eds.), Formas de difusión de las religiones antiguas, Madrid, 1993, p. 189-195.

D. PlÁcido, y M. VALDÉs, "Eleusis, el Ática y Atenas hasta la época de Pisístrato", Homenaje al profesor S. Lasso de la Vega, Madrid, 1998, p. 469-481.

C. Plichon, "Le Rhésos et l'orphisme", Kernos 14 (2001), p. 11-21.

G.A. PRIVITERA, Laso di Ermione, Roma, 1965.

G. RICCIARDIELLI, Inni Orfici, Roma, 2000.

N.J. RichaRDSON, The Homeric Hymn to Demeter, Oxford, 1974.

N. RoberTSOn, "New Light on Demeter's Mysteries: The Festival Proerosia", GRBS 37 (1996), p. 319-379.

L.E. ROLLER, In Search of God the Mother. The Cult of Anatolian Cybele, Berkeley / Los Angeles / London, 1999.

J. Rudhardt, "Les deux mères de Dionysos, Perséphone et Sémélé dand les Hymnes Orphiques", RHR 219, fasc. 4 (2002), p. 483-501.

P. SCARPI, (ed.), Le religioni dei Misteri, vol. I. Eleusi, Dionisismo, Orfismo, Roma, 2002.

A. SCHACHTER, "Kadmos and the implications of the tradition for Boiotian History", in La Béotie Antique, Lyon-Saint-Étienne, mai 1983, Paris, 1985, p. 145-153.

K. SCHEFOLD, "Statuen aus Vasenbildern", JDAI 52 (1937), p. 30.

R. SEAFORD, "Dionysiac Drama and the Dionysiac Mysteries", CQ 31 (1981), p. 252-275.

G.S. SFAMENi GaSParo, Misteri e culti mistici di Demetra, Roma, 1986.

H.A. ShapIro, "Paintings, Politics and Genealogy: Peisistratos and the Neleids", in W.G. MOON (ed.), Ancient Greek Art and Iconography, Madison, 1983, p. 87-96.

—, "Amazons, Thracians, and Scythians", GRBS 24 (1983), 105-114 (1983b).

-, Art and Cult under the Tyrants in Athens, Mainz, 1989

—, "Oracle-Mongers in Peisistratid Athens", Kernos 3 (1990), p. 335-345.

R.M. SimMs, Eleusinian-Athenian cult and myth: their nature and origin, Diss. Virginia (microfilms), 1980

E. Simon, "Neue Deutung zweier eleusinischer Denkmäler des vierten Jahrhunderts v. Chr.", $A K 9$ (1966), p. 72-92.

-, "Eleusis in Athenian Vase-painting: New Literature and Some Suggestions", in J.H. OAKLEY, W.D.E. Coulson, O. Palagia (eds.), Athenian Potters and Painters, Oxford, 1997, p. 97-108.

F. SOKOLOWSKI, Lois sacrées des cités grecques, Paris, 1969.

Ch. Sourvinou-Inwood, "What is Polis Religion?", in R. BuxTON (ed.), Oxford Readings in Greek Religion, Oxford, 2000, p. 295-322 (2000a).

-, "Further aspects of Polis Religion?", in R. BUXTON (ed.), Oxford Readings in Greek Religion, Oxford, 2000, p. 38-55 (2000b). 
P.G. Themelis, "The Cult Scene on the Polos of the Siphnian Karyatid at Delphi", in The Iconography of Greek Cult in the Archaic and Classical Periods, Athènes / Liège, 1992 (Kernos, suppl. 1), p. 49-72.

H.A. Thompson, "Buildings on the West Side of the Agora", Hesperia 6 (1937), p. 1-226.

G. Thomson, Aeschylus and Athens. A Study in the social origins of drama, New York, 1972 [1940].

M. TORTORelli Ghidini, StORchi Marino, A, Visconti, (eds.), Tra Orfeo e Pitagora. Origini e incontri di cultura nell'Antichità. Atti dei seminari Napolitana 1996-1998, Napoli, 2000, p. 161-194.

J. Travlos, Pictorial Dictionnary of Ancient Athens, London, 1971

M. VALDÉS Guía, "El nacimiento del orfismo en el ámbito del dionisismo ático: el mito del desmembramiento de Dioniso niño", Homenaje a José María Blázquez VI, Madrid, 1998, p. 303-325.

- Política y religión en Atenas arcaica. La reorganización de la polis en época de Solón, Oxford, 2002 (BAR International Series, 1018) (2002a).

—, "La exégesis en Atenas arcaica y clásica", Mediterraneo Antico, Anno V, fasc., 1 (2002), p. 185245 (2002b).

-, "El culto a Zeus y a las Semnai en Atenas arcaica: Exégesis eupátrida y purificación de Epiménides", Ostraka 11, n. 1 (2002), p. 223-243 (2002c).

—, "Los Cérices en Atenas arcaica y los Misterios de Agras: korynephoroi de Pisístrato e iniciación eleusina", Congreso Internacional de GIREA XXVII y ARYS VIII, Valladolid, 2004, p. 169-184.

A. Verbanck-PIÉRARD, "Heracles at Feast in Attic Art: a Mythical or Cultic Iconography?", in The Iconography of Greek Cult in the Archaic and Classical Periods, Athènes / Liège, 1992 (Kernos, suppl. 1), p. 85-106.

—, "Héraclès l'Athénien", in A. Verbanck-Piérard, D. Viviers (eds.), Culture et Cité. L'avènement d'Athènes à l'époque archaïque, Bruxelles, 1995, p. 104-125.

M.L. West, The Orphic Poems, Oxford, 1983.

R.E. WyCHERLEY, "The Pythion at Athens", AJA 67 (1963), p. 75-79.

—, "The Olympieion at Athens", GRBS 5 (1964), p. 161-179.

E. WiLl, "Aspects du culte et de la légende de la grande Mère dans le monde grec", in Éléments orientaux dans la religion grecque ancienne (Colloque de Strasbourg 22-24 mai 1958), Paris, 1960, p. 95-111.

D. Williams, "Herakles, Peisistratos and the Alcmeonids", in F. Lissarrague, F. Thélamon (eds.), Image et Céramique grecque, Rouen, 1983, p. 131-142.

S. WOODFORD, "Cults of Heracles in Attica", in D. GORDON et al. (eds.), Studies Presented to G.M.A. Hanfmann, Mainz, 1971, p. 211-225.

G. Zuntz, Persephone. Three Essays on Religion and Thought in Magna Grecia, Oxford, 1971. 